\title{
The Role of the First Postmitotic Cortical Cells in the Development of Thalamocortical Innervation in the Reeler Mouse
}

\author{
Zoltán Molnár, ${ }^{1}$ Richard Adams, ${ }^{1}$ André M. Goffinet, ${ }^{2}$ and Colin Blakemore ${ }^{1}$ \\ 1 University Laboratory of Physiology, Oxford OX1 3PT, United Kingdom, and 2Faculté de Médecine, Département de \\ Physiologie Humaine, Facultés Universitaires Notre-Dame de la Paix, 5000 Namur, Belgium
}

In the mutant mouse reeler, the tangential distribution of thalamocortical fibers is essentially normal, even though neurons of the cortical plate accumulate below the entire earlyborn preplate population (Caviness et al., 1988). This seems incompatible with the hypothesis that cells of the subplate (the lower component of the preplate in normal mammals) form an axonal scaffold that guides thalamic fibers and act as temporary targets for them (Blakemore and Molnár, 1990, Shatz et al., 1990).

We used carbocyanine dyes to trace projections in wild-type and reeler mice between embryonic day 13 and postnatal day 3. Preplate formation and early extension of corticofugal fibers to form a topographic array are indistinguishable in the two phenotypes. So too are the emergence of thalamic axons in topographic order through the primitive internal capsule, their meeting with preplate axons, and their distribution over the preplate scaffold. Distinctive differences appear after the cortical plate begins to accumulate below the preplate of reeler, causing the preplate axons to form oblique fascicles, running through the cortical plate. Thalamic axons then pass through the plate within the same fascicles and accumulate in the "superplate" layer for $\sim 2-3 \mathrm{~d}$, before defasciculating and plunging down to terminate deep in the cortical plate, creating the curious "looping" pattern seen in the adult. Thus, thalamocortical innervation in reeler follows the same algorithm of development but in relation to the misplaced population of early-born neurons. Far from challenging the theory that preplate fibers guide thalamic axons, reeler provides strong evidence for it.

Key words: cortex; reeler; development; pioneer axons; preplate; "handshake hypothesis"; thalamus; mouse; subplate; axon guidance; internal capsule
There is evidence that the distribution and subsequent behavior of thalamocortical axons in the rat involve crucial interactions with early postmitotic cortical neurons (see preceding paper; Molnár et al., 1998). These cells, which form the primordial plexiform zone (Marin-Padilla, 1971, 1988) or preplate (Rickmann et al., 1977; Stewart and Pearlman, 1987), send out pioneering axons (McConnell et al., 1989; De Carlos and O'Leary 1992; Erzurumlu and Jhaveri 1992), forming a "scaffold" (McConnell et al., 1989) that may act as a guidance structure for subsequent axonal growth (Blakemore and Molnár, 1990, Shatz et al., 1990). In normal mammals, the preplate is split into marginal zone above and subplate below, by the arrival, in between, of cells of the cortical plate proper, which accumulate in an inside-out fashion (Marin-Padilla, 1971; König et al., 1977; Luskin and Shatz, 1985a,b). In the rat, thalamic afferents and preplate efferents, mainly from the subplate, meet in the basal telencephalon; they intermingle, and thalamic fibers grow over the preplate axons to their target area (Molnár et al., 1998).

Subplate cells also seem to act as sites of transient termination of thalamic fibers (Shatz et al., 1988), while they "wait" for the cortex above to develop growth-permissive properties (Götz et

Received March 3, 1998; revised May 8, 1998; accepted May 14, 1998.

This work was supported by grants from the Medical Research Council (MRC), the Wellcome Trust, the Soros-Hungarian Academy of Sciences Foundation, Human Frontier Science Program, and Merton College (Oxford, UK). It forms part of the work of the Oxford McDonnell-Pew Centre and the MRC Interdisciplinary Research Centre for Cognitive Neuroscience, for which R.A. is a Research Scientist. Z.M. held an MRC Training Fellowship. We thank Laurence Waters, Lorraine Chappell, and William Hinkes for assistance with photography.

Correspondence should be addressed to Zoltán Molnár, University Laboratory of Physiology, Parks Road, Oxford OX1 3PT, UK.

Copyright (C) 1998 Society for Neuroscience $\quad 0270-6474 / 98 / 185746-20 \$ 05.00 / 0$ al., 1992; Molnár and Blakemore, 1995). In carnivores and primates this waiting period lasts for several weeks (Rakic, 1976, 1977; Shatz and Luskin, 1986; Ghosh and Shatz, 1992). In rodents, some thalamic fibers quickly penetrate a short distance into the cortical plate (Catalano et al., 1991, 1996; Kageyama and Robertson, 1993), but many accumulate in the subplate for 2-3 d before growing up into the plate (Molnár et al., 1998) and terminating mainly in layer 4 , the principal target of thalamic innervation (Jones, 1985).

Reeler, an autosomal recessive mutation of mouse with disorganized cerebral lamination (Caviness and Sidman, 1973; Caviness, 1976, 1982; Caviness and Rakic, 1978; Goffinet, 1979, 1984, 1995; Rakic and Caviness, 1995), provides a test bed for hypotheses about thalamocortical development. The molecular basis of the reeler trait is being unraveled (Bar et al., 1995; D'Arcangelo et al., 1995; Hoffarth et al., 1995; Ogawa et al., 1995), and its effects on cortical cell migration, architectonics, and connectivity are well known (Caviness et al., 1988). In reeler, the preplate initially forms apparently normally (Goffinet, 1979; 1980; Goffinet and Lyon, 1979; Pinto-Lord and Caviness, 1979; Caviness, 1982), but neurons of the cortical plate fail to divide the preplate into a marginal zone and subplate. Instead they gather in a somewhat irregular, outside-in sequence, entirely below the early-born cells, which are therefore left stranded above the plate itself in what has been termed the "superplate" (Caviness, 1982). Despite this aberrant location of the neurons that are hypothesized to guide them, thalamic axons reach appropriate cortical areas in reeler (Dräger, 1976; Steindler and Colwell, 1976; Caviness and Frost, 1980; Simmons and Pearlman, 1982) and terminate principally on neurons that correspond to layer 4 (Frost and Caviness, 1980). 
Table 1. Numbers of animals studied, phenotypes, and dye placement sites

\begin{tabular}{|c|c|c|c|c|c|}
\hline \multirow[b]{2}{*}{ Age } & \multirow{2}{*}{$\begin{array}{l}\text { Wild-type } \\
(\mathrm{rl} /+ \text { or }+/+)\end{array}$} & \multirow[b]{2}{*}{ Uncertain phenotype } & \multirow[b]{2}{*}{ Reeler $(\mathrm{rl} / \mathrm{rl})$} & \multicolumn{2}{|l|}{ Dye placements } \\
\hline & & & & Hemisphere 1 & Hemisphere 2 \\
\hline \multicolumn{6}{|c|}{5 litters from $\mathrm{rl} /+\times \mathrm{rl} / \mathrm{rl}$ parents } \\
\hline E13.5 & 2 & 8 & 2 & Cortex & Thalamus \\
\hline E14 & 3 & & 5 & Cortex & Thalamus \\
\hline E15 & 5 & & 6 & Cortex & Thalamus \\
\hline E18 & 4 & & 6 & Cortex & Thalamus \\
\hline $\mathrm{P} 1.5$ & 3 & & 4 & Thalamus & Thalamus \\
\hline \multicolumn{6}{|c|}{5 litters from $\mathrm{rl} /+\times \mathrm{rl} /+$ parents } \\
\hline E13 & & 6 & & Internal capsule & Thalamus \\
\hline E13.5 & 1 & 8 & 3 & Internal capsule & Thalamus + cortex \\
\hline E14 & 6 & & 5 & Internal capsule & Internal capsule \\
\hline E14.5 & 12 & & 2 & Internal capsule & Thalamus \\
\hline $\mathrm{P} 3$ & 5 & & 1 & Thalamus & Thalamus \\
\hline \multicolumn{6}{|c|}{2 litters from $\mathrm{rl} / \mathrm{rl} \times \mathrm{rl} / \mathrm{rl}$ parents } \\
\hline E14.5 & & & 10 & Internal capsule & Thalamus \\
\hline E18 & & & 5 & Internal capsule & Thalamus \\
\hline
\end{tabular}

However, the trajectory of thalamic axons within the adult cortex is highly abnormal, running up through the entire thickness of the cortex in obliquely oriented fascicles and looping down again into presumptive layer 4 (Caviness, 1976).

We have studied the interactions between thalamic axons and precocious cortical neurons in reeler and examined the way in which normal regional and laminar targeting are achieved by thalamic fibers despite the gross mislocation of their presumptive guidance cells.

\section{MATERIALS AND METHODS}

We used techniques similar to those used previously to study normal development in the rat (Molnár and Blakemore 1990, 1992), which are described in detail in the preceding paper (Molnár et al., 1998). Carbocyanine dyes were used to trace axon pathways in fixed brains of phenotypical wild-type and reeler mice of various gestational ages, from embryonic (E) day 13 to postnatal (P) day 3 (Table 1). We examined 12 litters (112 individuals altogether) from time-mated female mice. Pregnancies were dated by inspection for the vaginal plug, and the day of the plug was taken as E0. Forty-eight animals (five litters) were born from heterozygous $(\mathrm{rl} /+)$ females that had been mated with homozygous $(\mathrm{rl} / \mathrm{rl})$ males; and 49 individuals came from five litters for which both father and mother were heterozygous $(\mathrm{rl} /+)$. The first five litters thus contained $\sim 50 \%$ reeler and $50 \%$ normal, whereas the latter five litters consisted of $\sim 25 \%$ reeler and $75 \%$ normal, providing wild-type animals as controls at developmental stages exactly matched with those of the reeler specimens. Two further litters (15 pups) came from homozygous reeler parents $(\mathrm{rl} / \mathrm{rl})$ and therefore were all reeler (Table 1$)$.

Fetuses were removed by cesarean section under pentobarbital anesthesia $(100 \mathrm{mg} / \mathrm{kg}$, i.p., to the pregnant female). Deep anesthesia was maintained by immediate chilling on ice, and the fetus were perfused with $4 \%$ paraformaldehyde and $0.1 \%$ glutaraldehyde in $0.1 \mathrm{~m}$ phosphate buffer, $\mathrm{pH}$ 7.4, delivered intracardially through a glass micropipette under a dissecting microscope. Postnatal animals (at P1.5 and P3, counting the day of birth as $\mathrm{P} 0$ ) were anesthetized by chilling. The brains were removed, and, after a few days of post-fixation in $4 \%$ buffered paraformaldehyde, both hemispheres were used for axon tracing with carbocyanine dyes. One or more tiny individual crystals $(0.1-0.3 \mathrm{~mm}$ diameter) of dye were inserted, under an operating microscope, into the diencephalon (after transsecting the brainstem rostral to the colliculi) or the cerebral cortex, using a fine pair of forceps or a fine stainless steel wire. The dyes used were 1,1'-dioctadecyl 3,3,3'3'-tetramethylindocarbocyanine perchlorate (DiI), 4-[4-(dihexadecylamino)stryryl]- $N$-methylpyridinium iodide (DiA), 4-[4-(didecylamino)styryl]- $N$-methylpiridinium iodide
(DiASP)- and 3,3'-dipentyloxacarbocyanine iodide (DiO) (Molecular Probes, Eugene, OR). Table 1, right column, gives a summary of the sites of crystal placement.

All litters except the two from homozygous parents (Table 1) contained both reeler $(\mathrm{rl} / \mathrm{rl})$ and wild-type genotypes $(\mathrm{rl} /+$ or $+/+)$. Because it was impossible to distinguish between them on the basis of the gross appearance of their brains, all members of each litter were used for the same procedure, on the assumption that some of them were reeler. The fact that mutant individuals could be identified only after all the experimental procedures had been completed guaranteed objectivity: the experiments were essentially performed "blind."

In the mouse, as in the rat (Bayer and Altman, 1991), a spatiotemporal wave of maturation sweeps across the hemisphere. Throughout forebrain development in the mouse, anteroventral regions lead posterodorsal by about $1 \mathrm{~d}$ in the state of maturation. Before E13.5, the extremely immature cortex looked identical in all specimens; the preplate was present, but the cortical plate itself had not yet begun to appear, even in the most mature, rostrolateral segment of the hemisphere. Because there were no obvious differences between individuals in the appearance of the cerebral wall, none of the E13 embryos $(n=6)$ could be classified by conventional histological criteria (Goffinet, 1979, 1980; Pinto-Lord and Caviness, 1979; Stanfield and Cowan, 1979; Derer and Nakanishi, 1983). At E13.5 $(n=24)$ discrimination was also often impossible, although in eight individuals (five reeler and three wild-type) we were able to distinguish the genotypes with confidence by looking at the more mature, anterior and ventral regions of the hemisphere, where the first signs of the cortical plate itself could be detected (Fig. $1 B, E$ ). In these individuals we were therefore able to examine the organization of corticof ugal and corticopetal projections of the occipital cortex in identified reeler and wild-type specimens before the distinguishing characteristics of the cortex itself had begun to appear in that region.

The development of embryos within the same horn of the uterus can vary somewhat according to the number and location of the embryos. For embryos from small litters or from close to the distal end of the uterine horn, development is usually somewhat more advanced. This explains why it was possible to detect differences in some but not all brains from the same E13.5 litters.

In stages older than E13.5 the phenotypes could be readily distinguished after bisbenzimide counterstaining, even in sections of the relatively immature occipital cortex. In the normal mouse $(\mathrm{rl} /+$ and $+/+)$ a thin, cell-dense cortical plate is visible, sandwiched between two cell-sparse layers - the marginal zone above and the subplate below. In the reeler $(\mathrm{rl} / \mathrm{rl})$, there is less obvious variation in cell density; in particular there is no distinct boundary at the bottom of the cortical plate (see Results and Fig. 1 for more details).

From E14 onward, when the phenotype could always been identified, 21 individuals $(58 \%)$ were reeler $(\mathrm{rl} / \mathrm{rl})$, and $15(42 \%)$ were normal $(\mathrm{rl} /+)$ 

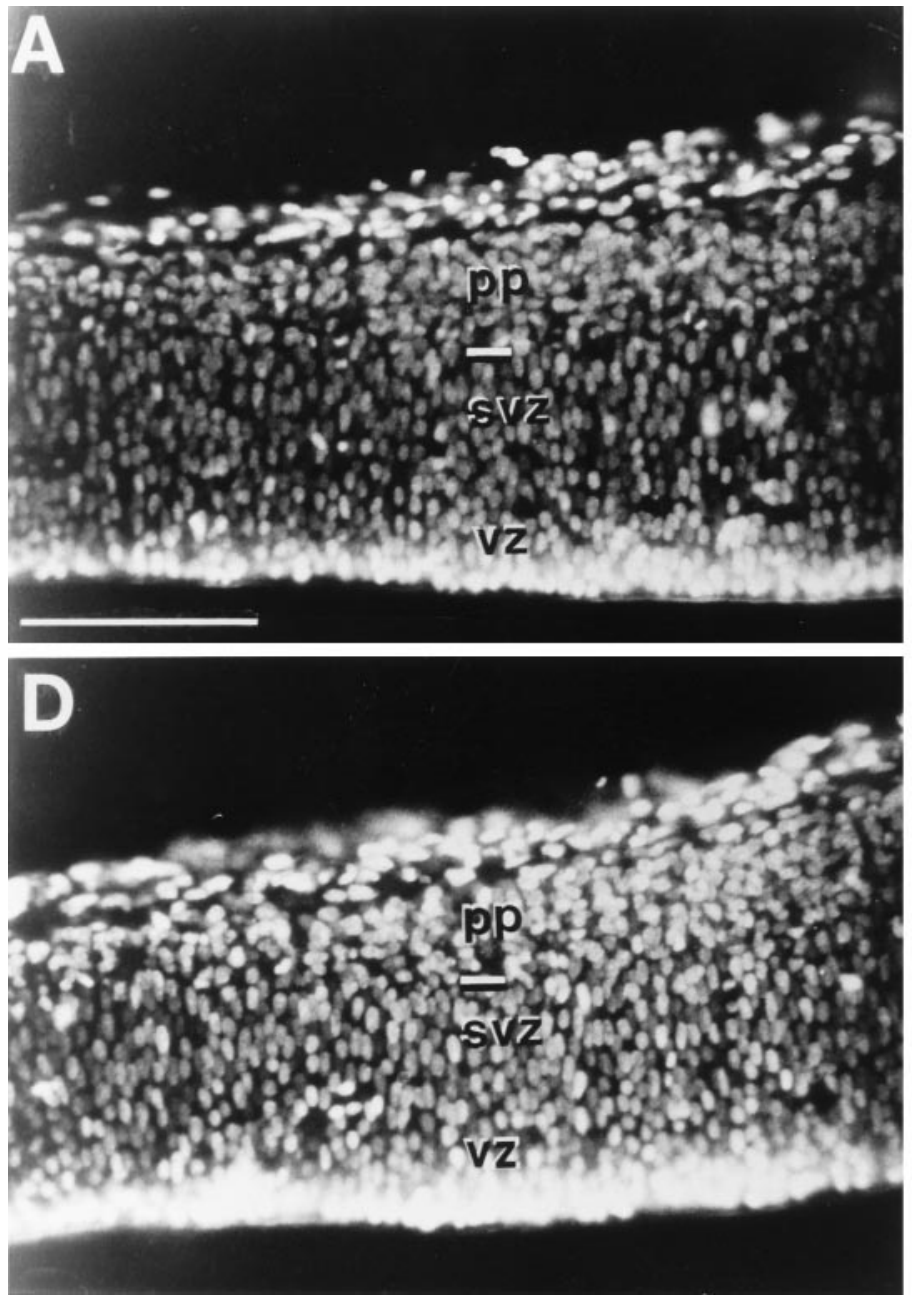
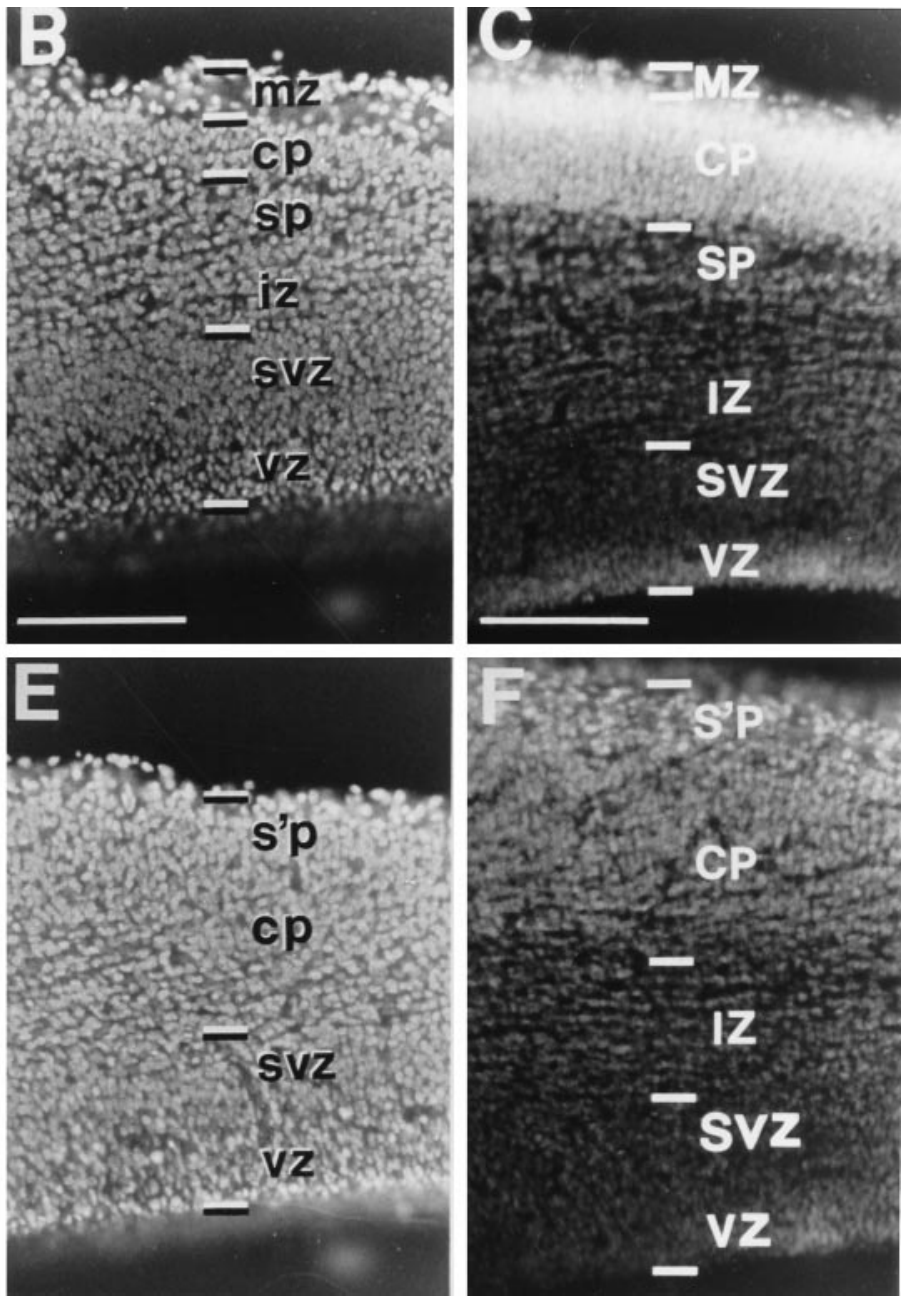

Figure 1. Coronal sections through the entire thickness of the cerebral wall (pial surface $u p$ ), stained with bisbenzimide, to show the appearance of the cell layers at E13.5 in a wild-type mouse $(A, B)$ and a reeler mouse $(D, E)$ and at E15 in a wild-type mouse $(C)$ and a reeler mouse $(F)$. The age-matched pairs are from the same litter. $A$, In the less mature occipital cortex of the E13.5 wild-type specimen, no cells of the cortical plate have yet arrived, and only the loosely packed cells of the preplate $(p p)$ are seen at the outer edge of the cerebral wall. $B$, In the most mature, rostrolateral part of the hemisphere of the wild-type animal, the first immature neurons of the emerging cortical plate $(c p)$ have just started to arrive and have interposed themselves between the thin, cell-sparse marginal zone $(\mathrm{mz})$ above and the subplate $(\mathrm{sp})$ below. Below the nascent intermediate zone $(i z)$ are the generative cells of the subventricular zone $(\mathrm{svz})$ and ventricular zone $(v z)$. D . The cerebral wall of the occipital cortex in the reeler at E13.5 also has only the preplate layer above the subventricular zone. With these techniques it is indistinguishable from the same area of the cortex in the wild-type animal (compare with $A$ ). E, In the same E13.5 reeler specimen, the characteristic aberrant appearance of the cortex is already recognizable here in the most mature rostrolateral segment of the hemisphere. The first cells of the cortical plate are beginning to accumulate, loosely packed, in an outside-in sequence, below the original preplate, which now forms what Caviness (1982) has termed the "superplate" ( $s$ 'p). No clear border is apparent between superplate and cortical plate at this early stage. Eight of the 24 brains examined at E13.5 could be reliably distinguished in this way, from the appearance of the rostrolateral cortex; in those specimens, the development of thalamocortical and corticof ugal projections toward and away from the occipital cortex could be studied in animals of identified phenotype before that region of cortex took on differentiated features. $C$, $F$, In these examples at E15, the two phenotypes can be clearly distinguished, even in the occipital cortex. In the normal animal $(C)$ the cell-dense layer of the cortical plate $(C P)$, already some $200 \mu \mathrm{m}$ thick, is sandwiched between two cell-sparse zones: the marginal zone $(M Z)$ above and the subplate $(S P)$ below. In the reeler $(F)$ there is no separate marginal zone, and the entire original preplate now forms the superplate $\left(s^{\prime} p\right)$, with the loose, obliquely striated cortical plate below. These cell-sparse stripes continue into the intermediate zone (IZ). By this stage every individual can easily be classified as reeler or wild type, even from sections of occipital cortex. In the reeler $(F)$ the superplate and cortical plate have similar cell density with no distinct boundary between them. The absence of a clear marginal zone and the less demarcated cortical plate, with its oblique cell-sparse striations, are reliable indicators of the reeler phenotype. $S V Z$, Subventricular zone; $V Z$, ventricular zone. Each pair of micrographs $(A, D ; B, E ; C, F)$ was taken at the same magnification. Scale bars, $200 \mu$ m.

in the litters from heterozygous females mated with homozygous males. And of 31 pups from heterozygous fathers and mothers, $8(26 \%)$ were reeler and $23(74 \%)$ were normal $(\mathrm{rl} /+$ or $+/+)$, close to theoretical expectation. All 15 specimens from the two litters with homozygous parents were confirmed to be reeler. Table 1 lists the numbers, gestational ages, genotypic backgrounds and, where identifiable, the phenotype of the mice in this study, as well as the locations of the dye placements.

After insertion of dye crystals, the brains were stored in PBS, with $0.1 \% \mathrm{Na}$ azide to prevent contamination, at room temperature, or at $37^{\circ} \mathrm{C}$ to facilitate the diffusion of dye along axons. Dye diff usion required different incubation periods depending on the age of the specimen and the temperature (Table 2).

At the end of incubation, the brains were embedded in $4 \%$ agar (made up in $0.9 \%$ saline) and cut by vibratome. Generally we used horizontal and coronal sectioning, but occasionally we cut stereotaxically vertical sections at an angle of $45^{\circ}$ to the coronal plane (see Figs. 6, 7) so that most of the pathway from the internal capsule to the cortex, in the middle of the hemisphere, could be followed within a single section. The sections, 75-200 $\mu \mathrm{m}$ thick, were counterstained with bisbenzimide (Riedel-De Haèn AG, Seelze-Hannover, Germany; $2.5 \mu \mathrm{g} / \mathrm{ml}$ in PBS) or 
Table 2. Carbocyanine dye incubation period in weeks

\begin{tabular}{lrr} 
& \multicolumn{2}{c}{ Incubation temperature } \\
\cline { 2 - 3 } Age of specimen & $20^{\circ} \mathrm{C}$ & $37^{\circ} \mathrm{C}$ \\
\hline E13-E15 & $3-4$ & $1-2$ \\
E15-E18 & 6 & 2 \\
P1.5-P3 & $6-8$ & $3-5$ \\
\hline
\end{tabular}

acridine orange $(10 \mu \mathrm{g} / \mathrm{ml}$ in PBS) for $10 \mathrm{~min}$, and coverslipped in Hydromount (National Diagnostics) or glycerol-phenylenediamine solution $(0.1 \%$ p-phenylenediamine, $10 \%$ PBS, and $90 \%$ glycerol, made up and stored according to the method of Johnson et al., 1982).

Each series of sections was examined in a conventional fluorescence microscope. Double- or triple-exposure color micrographs were taken under epifluorescent illumination, using different filters to reveal the various dyes. The counterstaining with bisbenzimide showed major anatomical features, such as the pial surface of the cortex, the bottom of layer 1 (in normal phenotypes), and the gray matter-white matter bound-
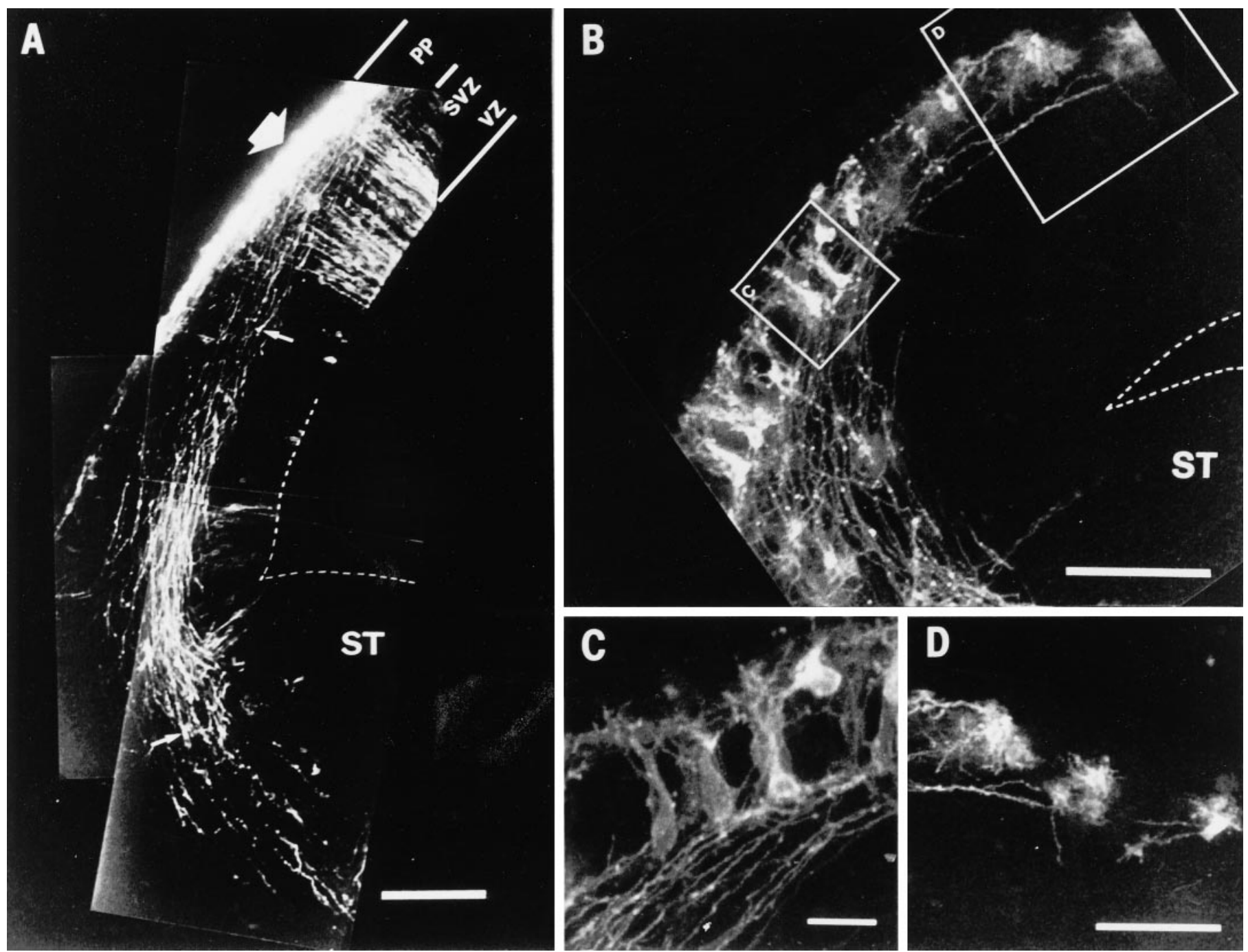

Figure 2. Origin of the first descending projection from the cortex, revealed by anterograde $(A)$ and retrograde $(B-D)$ labeling. $A$, Montage of confocal micrographs of a coronal section of the dorsolateral aspect of the hemisphere of an E13.5 mouse embryo. The boundary of the lateral ventricle is demarcated with an interrupted line. This individual was of reeler phenotype, judging from the appearance of the more mature, rostrolateral segment of the hemisphere (Fig. 1), although here in the occipital cortex, only the first postmitotic cells of the preplate $(P P)$ are present above the subventricular and ventricular zones $(S V Z, V Z)$. A small crystal of DiI had been inserted into the preplate, on the convexity of the cortex (large arrow). The thickness of this thin optical section was $2 \mu \mathrm{m}$, and it avoided the plane of the brightest part of the crystal placement, thus allowing the visualization of radial glia and spindle-shaped cells in the ventricular and subventricular zone. Labeled axons stream out of the preplate, forming a fairly tight bundle in the intermediate zone, with the most advanced of them (from more lateral parts of the labeled area of cortex) splaying out a little as they enter the anlage of the corpus striatum (ST). At this point the growth cones are particularly large and florid in morphology; one is indicated with a small arrow. Axons from more dorsal parts of the labeled area lie deeper in the intermediate zone and have grown less far. All 12 individuals treated in this way at this age ( 2 definitely identified as reeler, 2 as wild type) were remarkably similar in the appearance of both the cerebral wall and the early descending projection. Scale bar, $100 \mu \mathrm{m}$. $B$, Confocal microscopic reconstruction of a similar region of the posterior cortex in another E13.5 animal of reeler phenotype. A small DiI crystal had been implanted in the lateral aspect of the primitive internal capsule to back-label the descending projection (in the absence of ascending thalamic fibers) and to reveal the morphology of the cells of origin in the preplate. Three-dimensional confocal microscopic reconstructions were made and, $322-\mu \mathrm{m}$-thick optical sections were superimposed to generate this image. The boundary of the lateral ventricle above the striatal anlage is indicated by interrupted lines. Note the back-labeled cells distributed through the full depth of the preplate and the highly ordered arrangement of their axons, those from more dorsal cortex running deep to those from more lateral areas. No cells of the true cortical plate have completed their migration at this stage. Again the appearance was very similar in the 12 members of this E13.5 litter (including one identified wild type and three definite reeler). Scale bar, $150 \mu$ m. $C, D$, High-power views from the segments indicated by outline boxes in $B$, showing cells and individual fibers at higher resolution. Note the parallel axons in $C$. Scale bars, $30 \mu \mathrm{m}$. 

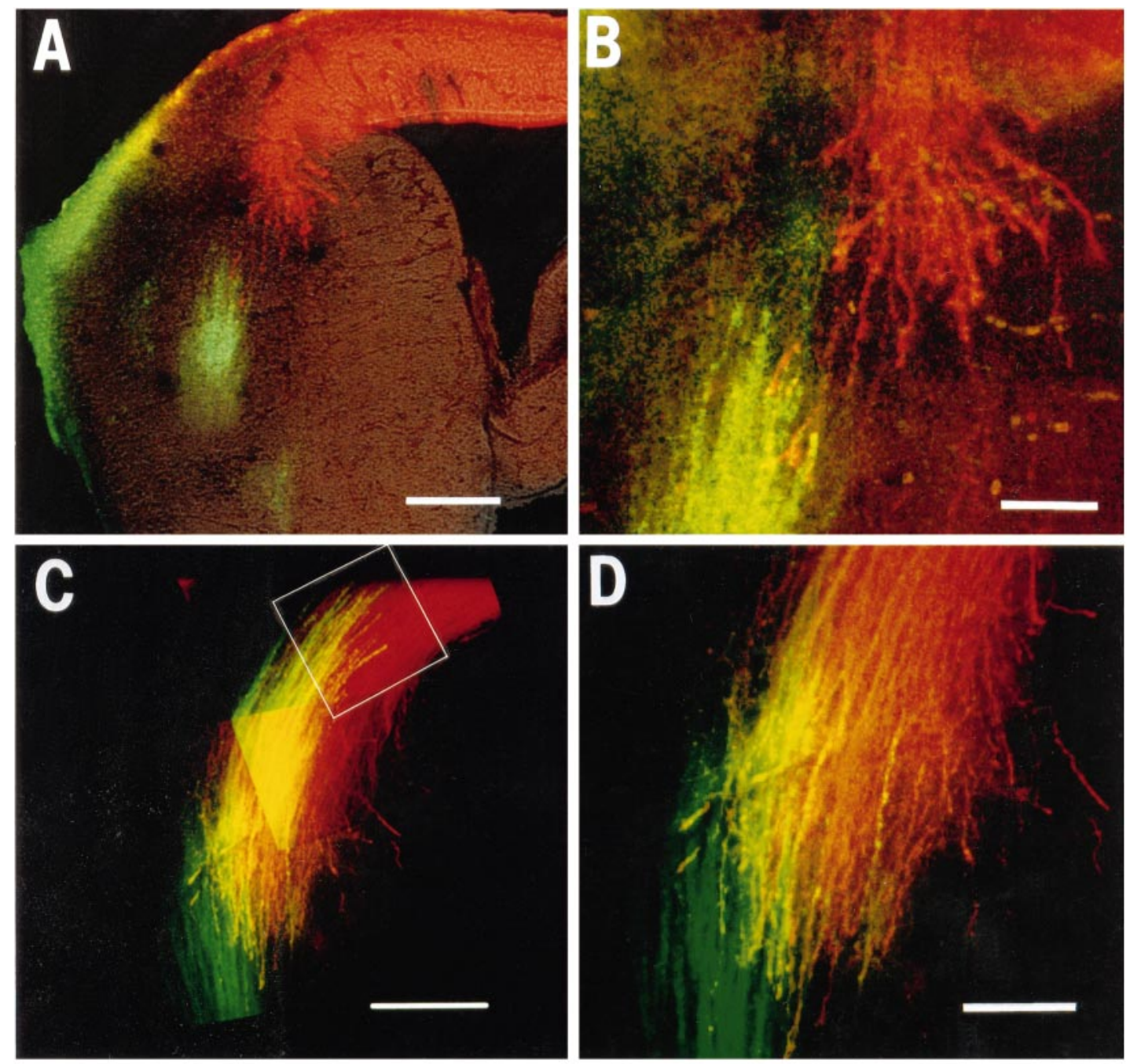

\section{E ( stereo - pair )}
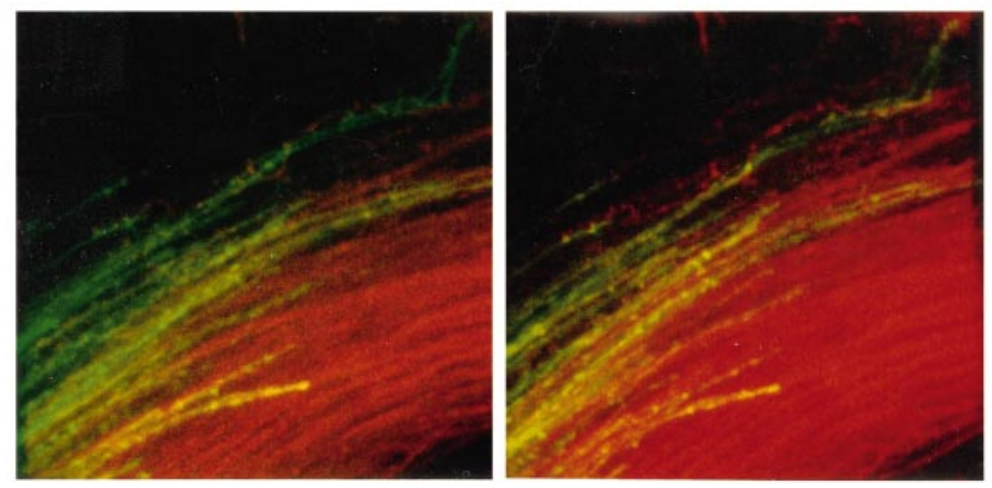

Figure 3. The earliest corticof ugal and thalamic projections meet and intermingle near the lateral margin of the striatal anlage. A small crystal of DiI (red) was placed in the convexity of the posterior cortex, and one of DiO (green) was placed in the dorsal thalamus of the same hemisphere in each member of a litter of E13.5 mice (12 individuals, 1 definitely identified as wild type, 3 as reeler). Fibers labeled with each dye were imaged in three dimensions by confocal microscopy. $A, B$, In this case, the early corticofugal axons (red) fan out from the intermediate zone and diverge somewhat as they sweep into the striatal anlage (compare with Fig. $2 A$ ). No back-labeled cell bodies are seen in the ganglionic eminence, implying that neurons in that region have not sent axons to the occipital cortex. The bundle of thalamic fibers (green), whose more medial portion, within the primitive internal capsule and diencephalon, is not visible in this section, have just reached the same region. (The green staining at the pial surface on the lateral side is an artifact.) The phenotype of this particular individual could not be judged with confidence, even from the most mature cortical (Figure legend continues.) 
ary. Many sections, selected in conventional fluorescence microscopy, were subsequently examined and imaged in a laser-scanning confocal microscope (CLSM-Fluovert; Leica, Heidelberg, Germany). Highresolution reconstructions of fiber pathways and back-labeled cells were generated from fine optical sections (up to 64 successive sections). These three-dimensional data sets were presented as extended focus projections or as stereo-pairs with $\pm 7^{\circ}$ disparity (see Fig. $3 E$ ).

\section{RESULTS}

The genesis of the cortex in normal mice is essentially similar to that in rats (for references, see Molnár et al., 1998), except that each step occurs about 1-2 d earlier in the mouse, whose total gestation lasts 19-20 d, compared with 21-22 d in the rat. Thus, for the occipital cortex of the normal mouse, the first postmitotic neurons are born in the ventricular zone at E12 and migrate to the outer edge of the cerebral wall by E13 to form the preplate. The birth of neurons of the cortical plate proper starts at about E13, and the first of them complete their migration at $\sim$ E13.5E14 (Sidman et al., 1959; Angevine and Sidman, 1961; Caviness, 1982).

The appearance of the material from wild-type $(\mathrm{rl} /+$ or $+/+)$ mice in the present study conformed at every stage to the previous descriptions of corticogenesis in normal mice. Moreover, we saw no difference between wild-type and reeler $(\mathrm{rl} / \mathrm{rl})$ until after the time of the arrival of the first neurons of the cortical plate, at E13.5-E14 (Goffinet, 1979, 1980; Pinto-Lord and Caviness, 1979; Stanfield and Cowan, 1979; Derer and Nakanishi, 1983).

Rapid Golgi, neurofilament immunohistochemical, and monoaminergic histofluorescence techniques have already been used to investigate some aspects of the development of the afferent connections in reeler (Caviness and Korde 1981, Yamamoto et al., 1986). Caviness et al. (1988) and Yuasa et al. (1994) described the targeting of the first generated cells in the subplate of normal mice and the superplate in reeler. However, the timing of outgrowth of early corticofugal axons and their relationship to thalamocortical projections have not been previously examined. The capacity of carbocyanine dyes to label axons and cells in fixed tissue, through passive anterograde and retrograde diffusion (Godement et al., 1987), provides a means of exploring the entire process of development of connections. Our description is based on 224 experiments, involving approximately equal numbers of wild-type and reeler specimens (Table 1).

\section{E13-E13.5: before the formation of the cortical plate}

We examined three litters at this gestational stage (total $n=30$ : 12 individuals at E13.5 from $\mathrm{rl} /+$ mothers and $\mathrm{rl} / \mathrm{rl}$ fathers; 6 at $\mathrm{E} 13$ and 12 at E13.5 from $\mathrm{rl} /+$ mothers and fathers). In eight of the E13.5 specimens (five reeler and three wild-type) we were able to discriminate between the phenotypes from the appearance of the most mature region of cortex in the ventral-anterior segment of the hemisphere (Fig. 1B,E), although the occipital cortex of even these individuals was still indistinguishable (Fig. $1 A, D$ ). The other specimens in this age group could not be reliably classified by any histological criteria in bisbenzimide-stained sections of cortex or thalamus. However, each litter presumably consisted of $\sim 50 \%$ wild-type and $50 \%$ reeler (for $\mathrm{rl} /+\times \mathrm{rl} / \mathrm{rl}$ matings) or $75 \%$ wild-type and $25 \%$ reeler (for $\mathrm{rl} /+\times \mathrm{rl} /+$ ). (Proportions close to these theoretical expectations were indeed seen in the older litters, in which the two genotypes could easily be recognized from the appearance of the cortex.) Fortunately, identification of phenotype was, in a sense, irrelevant, because we saw no obvious differences in the patterns of corticofugal and thalamofugal projections between individuals at this early stage (even for the eight definitely identified individuals, which we examined with particular care; Fig. 2). Thus, the description below applies to both reeler and normal mouse.

\section{Ordered outgrowth of preplate axons}

For all the E13.5 embryos, we placed a carbocyanine dye crystal in the cortex of one hemisphere (and in the 12 animals from heterozygous fathers we also implanted a crystal in the thalamus of the same hemisphere; see below). At this early stage the germinal ventricular zone consists of spindle-shaped neuroblasts, which generate cells destined for the cortex. The earliest born population of polymorphous daughter cells have already reached the outer edge of the cerebral wall to form the preplate, but the cortical plate itself has not begun to appear anywhere except in the most anterolateral segment of the hemisphere of some individuals.

The crystal placements in the occipital cortex revealed that many preplate neurons have already extended axonal processes, which run obliquely within the preplate layer, and into the intermediate zone. In Figure $2 A$, a distinct bundle of axons, with growth cones at their tips, extends downward toward the primitive internal capsule in an E13.5 reeler embryo (identified from the appearance of the anterolateral cortex). The pioneer fibers at the leading front of this bundle diverge somewhat as they enter the anlage of the corpus striatum (also see Fig. 3 below). Some of the growth cones are particularly large and have florid morphology.

\section{Cells of origin of the early corticofugal projection}

In one hemisphere of all the animals of the E13 and E13.5 litters from heterozygous fathers ( $n=6$ and 12, respectively), we placed a small DiI crystal into the primitive internal capsule, to backlabel the source of these early corticofugal fibers. These experiments demonstrated that the projections did indeed originate from typical preplate cells. Figure 2, $B-D$, illustrates these backlabeled cells in an identified reeler specimen, although their ap-

\section{$\longleftarrow$}

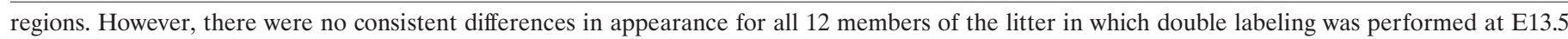

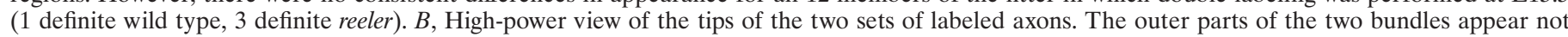

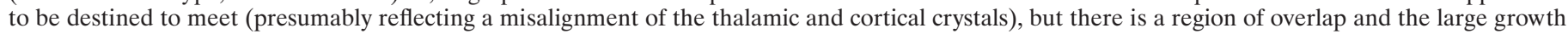

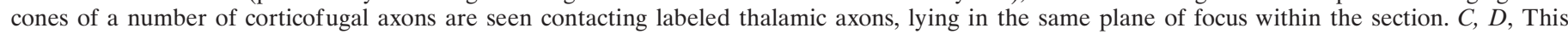

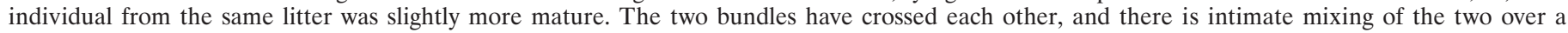

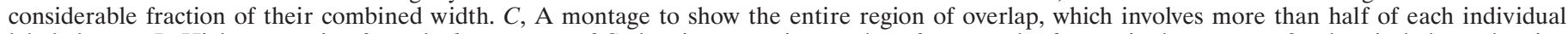

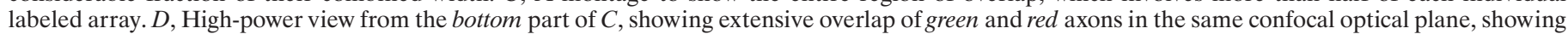

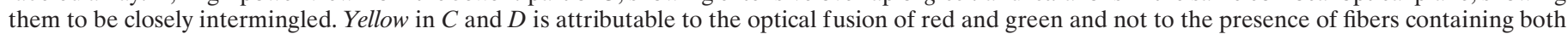

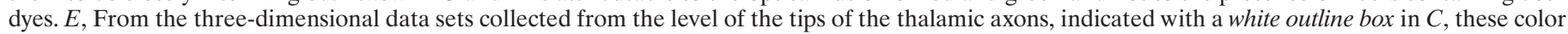

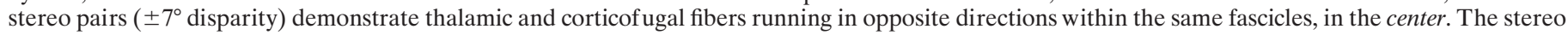
pair should be viewed by diverging the eyes or with the aid of prisms. Scale bars: $A, 250 \mu \mathrm{m} ; B, D, 100 \mu \mathrm{m} ; C, 200 \mu \mathrm{m}$. 

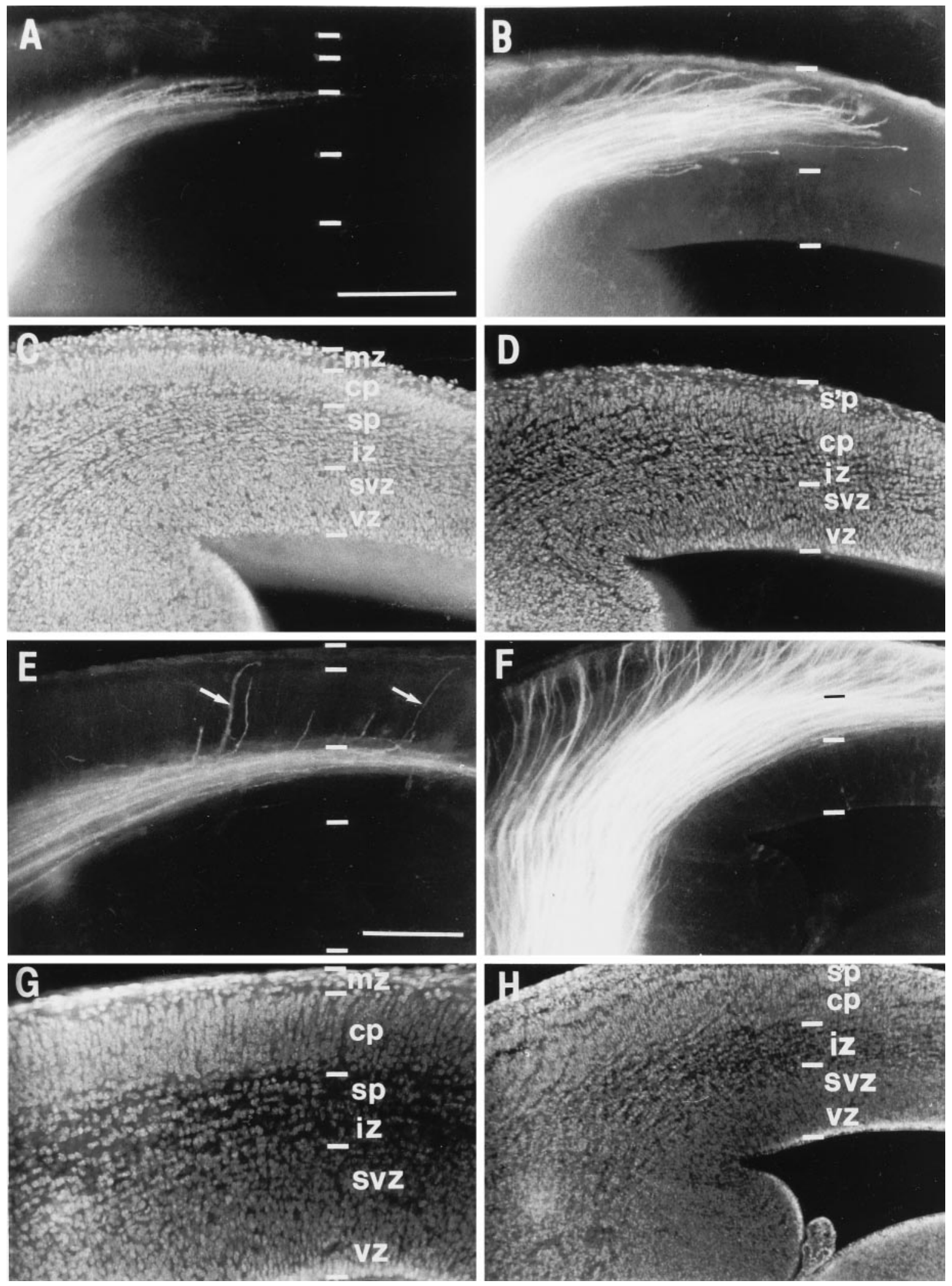

Figure 4. Comparison, in wild type and reeler, of the distribution of thalamic axons as they approach the cortex at E14.5 $(A-D)$ and E15 $(E-H)$. The left column $(A, C, E, G)$ shows results from wild-type animals, and the right column $(B, D, F, H)$ shows results from reeler. In each case a single DiI crystal had been placed in the dorsal thalamus, anterogradely labeling thalamocortical fibers. No back-labeled cells are seen in the cortex, implying that no corticof ugal axons have reached the dorsal thalamus. All micrographs were taken from similar sectors of the dorsolateral aspect of the left hemisphere in these coronal sections (lateral is up, dorsal is right). Below each fluorescence micrograph $(A, B, E, F)$ is a matched image showing bisbenzimide counterstaining $(C, D, G, H)$. Compare the obvious laminar arrangement in the normal cortex $(C, G)$ and the distinctive, abnormal appearance of the cortex in reeler $(D, H)$, with its loose, obliquely striated cortical plate $(c p)$ lying below the superplate (s'p) (compare with Fig. 2). (Figure legend continues.) 
pearance was indistinguishable at this stage in definite wild-type embryos. To resolve individual fiber ordering and to document the morphology of these cells, we examined these specimens by laser-scanning confocal microscopy (in addition to fluorescence microscopy). In both wild-type and reeler specimens, the backlabeled cells were typical polymorphous, polygonal preplate cells (Fig. 2B-D), distinctly different in morphology from the spindleshaped cells of the ventricular and subventricular zones visible in Figure $2 A$. The preplate cells have extensive dendritic arbors, and their overall appearance is more mature than that of cells in the ventricular and subventricular zones.

\section{Outgrowth of thalamic axons and their "handshake" with the corticofugal array}

In all 30 individuals studied at E13-13.5, we placed a crystal of dye in the dorsolateral aspect of the diencephalon (posterior dorsal thalamus) in one-half of the brain. (In the other hemisphere, either the internal capsule or the cortex was implanted with dye; Table 1.) These experiments revealed afferent axons from the thalamus, with growth cones at their tips, approaching the primitive internal capsule at E13 and just passing through it at E13.5.

For the litter of 12 E13.5 embryos from heterozygous fathers, in the hemisphere that received a crystal in the thalamus, we also placed a crystal of a different carbocyanine dye in the approximately corresponding position in the occipital cortex to provide a comparison of the state of corticofugal and corticopetal outgrowths. These double-labeling experiments show that the advancing wave fronts of the two sets of axons approach each other beneath and within the anlage of the corpus striatum at approximately E13.5 (Fig. 3). In the least mature examples, the two sets of axons are still a short distance apart; in some cases they are just making contact beneath the lateral ganglionic eminence (Fig. $3 A, B$ ); and in the most mature specimens of this age, the fiber systems have already extensively intermingled in the intermediate zone (Fig. 3C,D). High-power, thin optical sections from confocal microscopy, as well as three-dimensional data sets and stereoscopic images (Fig. 3E), showed both descending and ascending axons forming ordered arrays, sharing the same extracellular compartment and in intimate contact with each other. As in the normal rat (Molnár et al., 1998), the degree of overlap of the two arrays of labeled fibers varied from animal to animal, presumably reflecting the exact placement of the two dye crystals. But in all cases in which the axons had reached or passed each other, at least some part of the thalamic array was in close association with the labeled part of the corticofugal array within the intermediate zone. This pattern of approximately synchronized outgrowth and meeting of early corticofugal and corticopetal projections was observed in every member of this E13.5 litter, including the three identified as reeler and the one definite wild type.

\section{E14-E18: after the appearance of the cortical plate}

At E14, the first cells of the true cortical plate had begun to arrive in the occipital cortex. At this age, only $1 \mathrm{~d}$ or so after the appearance of the first postmitotic cells in the preplate, individual animals of the mixed litters were already easily distinguished as wild type or reeler, depending on whether the cells of the cortical plate were coming to rest within or below the preplate, respectively (Fig. $1 C, F$ ). In normal mice, the migration of true cortical neurons through the lower part of the preplate and their accumulation below the marginal zone create sharp boundaries between regions of different cell density, at the upper and lower limits of the expanding cortical plate. On the other hand, in reeler, the entire preplate layer stays intact at the outer edge of the cerebral wall to form the superplate, and the disorganized accumulation of cortical plate neurons below it does not produce a distinct boundary. Bisbenzimide counterstaining alone was quite adequate, at this and later stages, to reveal the characteristics of reeler - the irregular, unlaminated cortical plate, without a clear lower boundary and with a loose superplate layer above, rather than a clearly segregated marginal zone (Fig. $1 F$ ). Distinctive oblique, cell-sparse striations are also seen, extending through the full depth of the cortical plate, from the superplate above to the intermediate zone below (see Figs. $1 F, 4 H, 8 H$ ).

\section{Unusual behavior of thalamic fibers in reeler as they approach the cortex}

In each individual of six of the seven litters between E14 and E18 we placed a DiI crystal in the dorsal thalamus (see Table 1 for details). These thalamic tracing experiments revealed that at approximately E14, the bundle of regularly packed, labeled thalamic axons diverges slightly, loosens, and breaks up into a number of smaller fascicles, as they run through the anlage of the corpus striatum. Fibers from the dorsal thalamus reach the occipital pole at approximately E14.5-E15 in both reeler and normal phenotypes. At this stage the cortical plate itself is $\sim 100-150 \mu \mathrm{m}$ thick, whether accumulating above the subplate (in wild type) or below the superplate (in reeler). No difference between the two phenotypes in the organization of thalamocortical projections is evident at any point in the pathway through the diencephalon, the internal capsule within the striatal anlage, and the ventral intermediate zone.

Only as they approach the cortex itself do thalamic axons assume quite different patterns in the two genotypes (Fig. 4). In normal animals, just as in rats (see Molnár et al., 1998), a dense mass of thalamic fibers gathers in the subplate layer, and very few of them penetrate the cortical plate above. By contrast, in reeler, as shown in Figure $4, B$ and $F$, thalamic axons run through the cortical plate in diagonal fascicles, without branching or terminating, and they accumulate within the layer of superplate cells, which correspond to subplate neurons in the normal animal.

It is important to emphasize that the earliest neurons of the

\section{$\leftarrow$}

The DiI staining in the normal E14.5 animal $(A)$ shows an approximately parallel array of thalamic axons running through the intermediate zone $(i z)$ and entering the subplate $(s p)$. By comparison, in reeler at the same age $(B)$, thalamic fibers are growing up obliquely through the cortical plate, and some are already entering the superplate. At E15, the vast majority of axons in the normal animal $(E)$ are still restricted to the subplate layer, but in reeler $(F)$ they all appear to have passed through the plate and into the superplate above. Interestingly, in the selected image from the wild-type mouse ( $E$ ), in addition to a number of short branches entering the very bottom of the cortical plate, a few thalamic fibers (indicated with white arrows in $E$ ) can be seen growing more obliquely through the cortical plate all the way to the marginal zone, in a manner very similar to all the axons in reeler. svz, Subventricular zone; $v z$, ventricular zone. Scale bars, $200 \mu \mathrm{m}$ for all panels. 

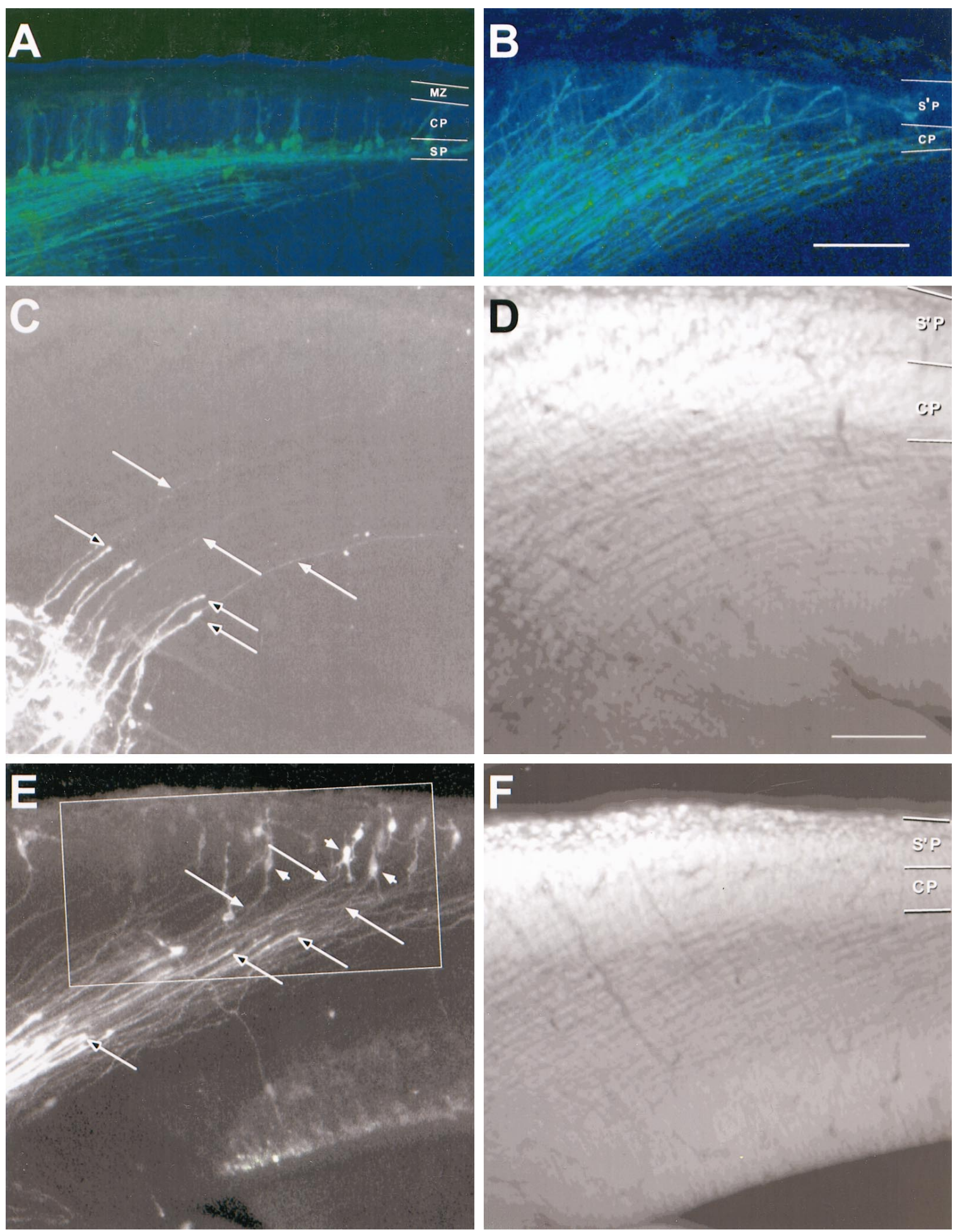

Figure 5. Here (and in Figs. 6, 7) the relationship among thalamocortical afferents, early corticofugal axons, and their cell bodies at E14.5 is seen in extended focus images of the cerebral wall of the left hemisphere made from thin optical sections collected by confocal microscopy (lateral is $u p$; dorsal is right). A small crystal of DiI in the internal capsule has labeled a restricted group of both classes of axon; they appear green. The sections are counterstained with acridine orange; cell nuclei appear blue. The blue background is a bright-field image showing the boundaries of the cerebral wall. $A, B$, Low-power images of examples of wild-type $(A)$ and reeler $(B)$ mice in which thalamic fibers have already reached the cortex. The mass of axons, forming a parallel array in the intermediate zone, is a mixture of thalamocortical axons (many of which can be traced in high power to growth cones at their tips) and early corticof ugal fibers (many of which can be followed back to the labeled cell bodies of origin. In the wild type $(A)$, the labeled cells lie almost exclusively in the subplate $(S P)$, with a very small number (some even with pyramidal morphology) in the cortical plate $(C P)$ and, in other sections, in the marginal zone $(M Z)$. In the reeler $(B)$ no back-labeled somata are seen below the cortical plate $(C P)$, through which both classes of axon run obliquely, up to the superplate $\left(S^{\prime} P\right)$ above, where labeled cell bodies are seen, specially at higher power (Fig. $\left.7 B\right)$. $C, D$ and $E, F$, Examples from a reeler specimen from another E14.5 litter. Sections were cut at $45^{\circ}$ to the coronal plane, approximately parallel to the labeled fibers over much of their course. The images on the left $(C, E)$ show stained axons, whereas those on the right $(D, F)$ show the acridine orange (Figure legend continues.) 
cortical plate proper have completed their migration by the time thalamic axons arrive in the vicinity of the target region of the cortex. Therefore, in reeler, thalamic axons must grow through at least a thin layer ( $\sim 100-150 \mu \mathrm{m}$ thick) of cortical plate cells to reach the superplate layer above. In the wild-type mouse, however, the cortical plate itself appears to be nonpermissive to ingrowth (as the rat cortex is, in vitro, at corresponding ages; Molnár and Blakemore, 1995). In general, only a few small side branches of thalamic axons penetrate the lowest part of the plate in the normal mouse (as in the rat; Molnár et al., 1998). However, a very small number of axons, some even forming fasciculated bundles, run up obliquely through the entire cortical plate and enter the marginal zone in some of the wild-type specimens (Fig. $4 E$ ), just like all the thalamic axons in reeler.

\section{Appearance of the axons of preplate cells close to their somata}

At this stage, neither the early corticofugal axons nor their cells of origin were back-labeled by dye crystals placed in the dorsal thalamus in either wild type or reeler. To examine the appearance of the early corticof ugal fiber trajectories as well as those of the newly arriving thalamic axons, we inserted DiI into the primitive internal capsule of both hemispheres in an E14 litter ( $n=11$; six wild-type, five reeler) and of one hemisphere in two E14.5 litters ( $n=29 ; 12$ wild-type, 17 reeler). In each member of the E14.5 litters, a crystal was placed in the dorsal thalamus of the other hemisphere, enabling us to compare, in the same specimens, the appearance of thalamic axons alone and thalamic fibers mixed with corticof ugal efferents (contrast Fig. $4 A-D$ with Figs. 5, 6).

Crystals placed in the internal capsule at E14.5 labeled both thalamocortical and early corticofugal projections within the telencephalon. In several cases we cut sections at $45^{\circ}$ to the coronal plane, which proved to be optimal for following single fibers in individual sections over much of their trajectory. In normal mice, the mixed axon tract, including descending axons that had emerged from subplate cells 1-2 d earlier, assumes a characteristic pattern - a broad sheet of approximately parallel axons extends through the intermediate zone and into the subplate, where many cell bodies are back-labeled (Fig. $5 A$ ).

Even in these wild-type specimens a few back-labeled cells with typical preplate morphology were also seen in the marginal zone at E14.5, with their efferent axons extending diagonally downward, through the cortical plate itself, joining the main group of corticofugal axons below the subplate. Thus axons from a small number of marginal zone cells in the normal mouse appear to reach at least the ventral telencephalon at this age, along with the main group of subplate fibers. The separation of subplate and marginal zone cells and the appearance assumed by their axons are entirely explained by the intrusion of cortical plate cells between these two divisions of the original preplate.

In reeler, the migratory arrest of true cortical plate neurons below the polymorphous neurons of the preplate leaves all the precocious efferent axons crossing diagonally through the thickening cortical plate (Fig. $5 B$ ), just like those of the rare axons of marginal zone cells seen in normal mice. They become organized into oblique fascicles, running between the cells of the cortical plate, presumably corresponding to the cell-sparse, diagonal striations typical of reeler cortex (see Figs. $1 F, 4 H, 8 H)$. Except for this difference in distribution in the region of the cortical plate itself, the trajectories of the early corticofugal axons are indistinguishable in reeler and normal mice at this and subsequent stages.

\section{Association between thalamic axons and preplate neurons}

At E14.5, shortly after thalamic axons have passed through into the intermediate zone, both ascending and descending fibers are labeled by a crystal in the internal capsule. Close to the implantation site, the stained fibers form a uniform dense mass, but in serial, high-power confocal images, many of them can be followed either to growth cones or back to labeled cell bodies in the cortex, unequivocally distinguishing them as thalamic or corticofugal, respectively. In both wild-type and reeler mice, just as in the rat (Molnár et al., 1998), identified thalamic axons appear stouter than cortical efferents within the intermediate zone (Figs. $6 \mathrm{~A}$, $7 C$ ). In every specimen, the two sets of axons form two completely overlapping, parallel arrays (Figs. 5, 6).

In cases in which the thalamic fibers have not progressed far into the intermediate zone, their tips are arranged across a broad front within the intermediate zone, distributed across the entire width of the array of thinner corticofugal axons (Fig. $5 C$ ), many of which can be traced, in the same or neighboring sections, back to labeled cell bodies in the cortex. Where thalamic axon growth is further advanced, the leading growth cones, still entirely interspersed within the array of corticofugal fibers, approach the cortex itself (Fig. 5E). Counterstaining with the chromatin stain acridine orange enabled us to distinguish indubitably between neuronal somata and the large growth cones of presumed thalamic axons, even when they were very close.

In fine confocal sections from some of the reeler specimens at E14.5, growth cones of the most advanced thalamic axons are seen approaching or entering the cortical plate itself, mixed in individual fascicles with the efferent axons of back-labeled superplate cells (Figs. 5B, $E, 6,7$ ). In some cases we saw an efferent axon running over a considerable distance in close association with an individual thalamic fiber, the terminal growth cone of which was approaching the back-labeled cell body in the superplate. The fortuitous example in Figure $7 D$ shows two axons running side by side, leading to the enormous growth cone of the thalamic fiber in actual contact with the soma of the superplate cell (identified as such by the acridine orange staining).

The high-resolution, extended focus image of stacked confocal sections in Figure $6 A$ (enlarged from the outlined area in Fig. $5 E$ ), shows a contingent of labeled thalamic fibers (several with clear growth cones at their tips) growing over the ordered

\footnotetext{
counterstaining, which reveals the characteristic loose cortical plate $(C P)$ below the superplate $\left(S^{\prime} P\right) . C, D$, Close to the crystal placement in the internal capsule, a broad array of thick thalamic axons with growth cones at their tips (unfilled arrows) has advanced only a short distance into the intermediate zone. They are superimposed on an array of much finer axons, only just visible at this magnification (some indicated with filled arrows), extending back up toward the cortex. Many of these could be traced, in adjacent sections, to back-labeled cell bodies in the superplate. $E$, $F$, Further rostral, where development is more advanced, the thick thalamic axons have advanced further. The growth cones of some of them (unfilled arrows) are seen entering the cortical plate, clearly superimposed on a carpet of finer corticof ugal axons ( filled arrows), which can be followed back to labeled bipolar and multiform cell bodies in the superplate (examples indicated with filled arrowheads). The region within the outline is shown at higher power in Figure 6. Confocal reconstructions: $A, B, 32$ sections $\times 2.0 \mu \mathrm{m}$ intervals; $D, 32 \times 5.8 \mu \mathrm{m} ; E, 30 \times 2.0 \mu \mathrm{m} ; D, 32 \times 3.3 \mu \mathrm{m}$. Scale bars, $100 \mu \mathrm{m}$ for all panels.
} 

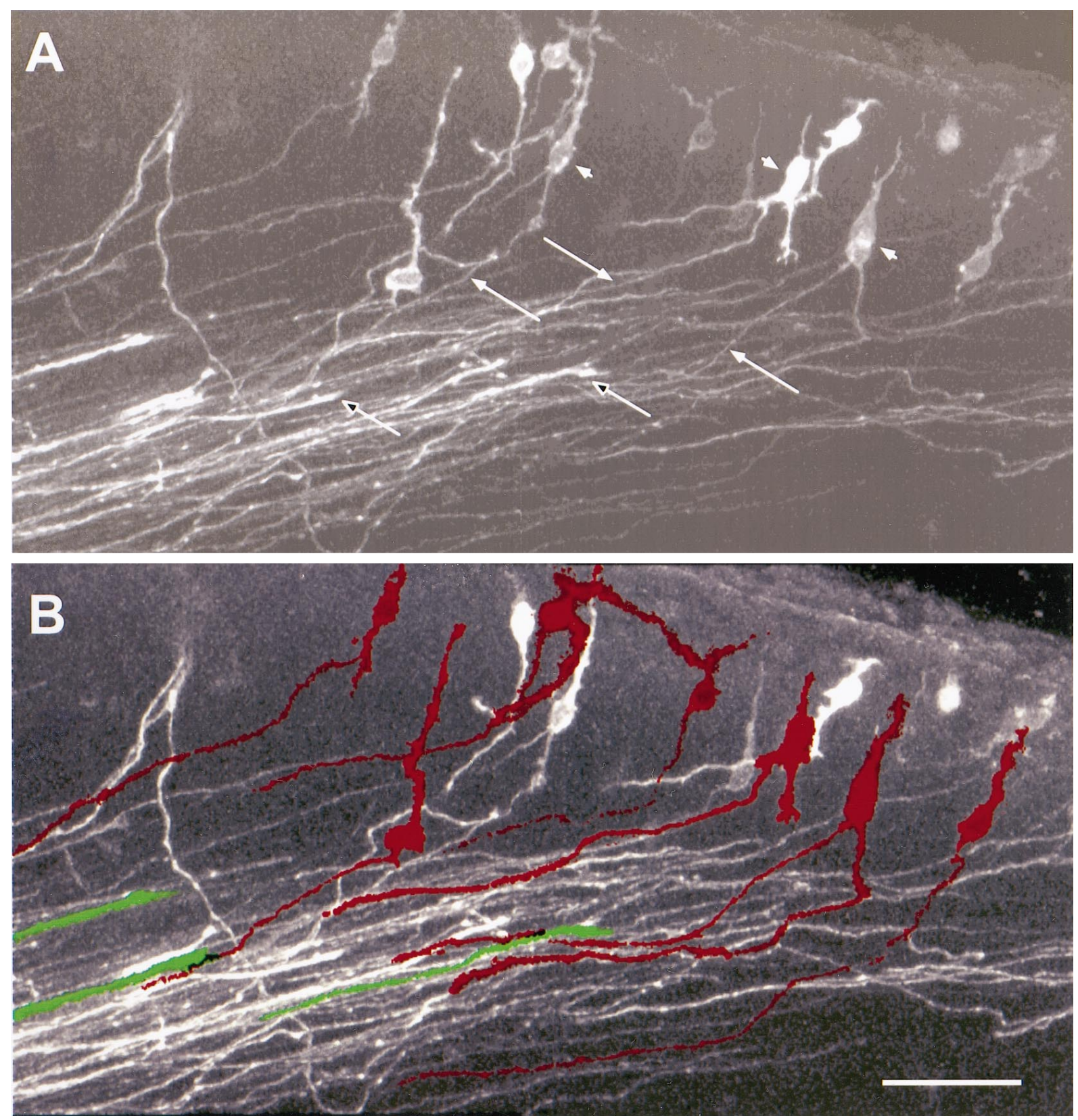

Figure 6. High-power view of the outlined area in Figure $5 E$, showing the early corticofugal projection and advancing thalamic axons, revealed by a single DiI crystal in the internal capsule of an E14.5 reeler mouse. This is an extended focus confocal image, from a $100 \mu \mathrm{m}$ section cut at $45^{\circ}$ to the coronal plane, approximately parallel to the mixed axon array close to the target area. $A$, In the raw image, the early efferent projection consists of a broad array of fine, approximately parallel axons ( filled arrows), streaming obliquely through the gathering cortical plate (compare with the counterstained view in Fig. $5 F$ ) and into the intermediate zone. Many of these thin axons clearly derive from back-labeled bipolar or multiform cell bodies, loosely arranged in the superplate below the pial surface ( filled arrowheads). Acridine orange counterstaining of the nuclei demonstrates that these structures are somata rather than growth cones. The stouter thalamic fibers, many of which can be definitively identified by growth cones at their tips within this section (unfilled arrows), are distributed across the full width of the carpet of superplate axons. They have advanced, parallel to and in very close association with the array of corticofugals, into the cortical plate to within $50 \mu \mathrm{m}$ of the superplate. $B$, In this processed image, individual examples of corticof ugal fibers and the cell bodies from which they originate have been infilled with red, whereas a few selected, identified thalamic axons are green. The outlines of axons, defined by a threshold of pixel contrast, were followed through the entire stack of thin optical sections. Examples that could be unequivocally traced to a cell body or a growth cone, within the three-dimensional data set, were then automatically infilled with the appropriate color and merged with the original image. Clearly thalamic fibers are tightly associated with the axons of superplate cells within individual fascicles running through the cortical plate. Scale bar, $50 \mu \mathrm{m}$.

array of parallel corticofugal axons and approaching their spindle-shaped or polymorphous cell bodies in the superplate. Figure $6 B$ is a processed version of the same image in which the profiles of a number of definite corticofugal axons have been infilled with red, along with the cell bodies from which they arise, and some identified thalamic fibers, ending in growth cones within this section, are filled with green. This shows without doubt that the two sets of fibers run in very close association within the same growth compartment, right up to the superplate layer. 

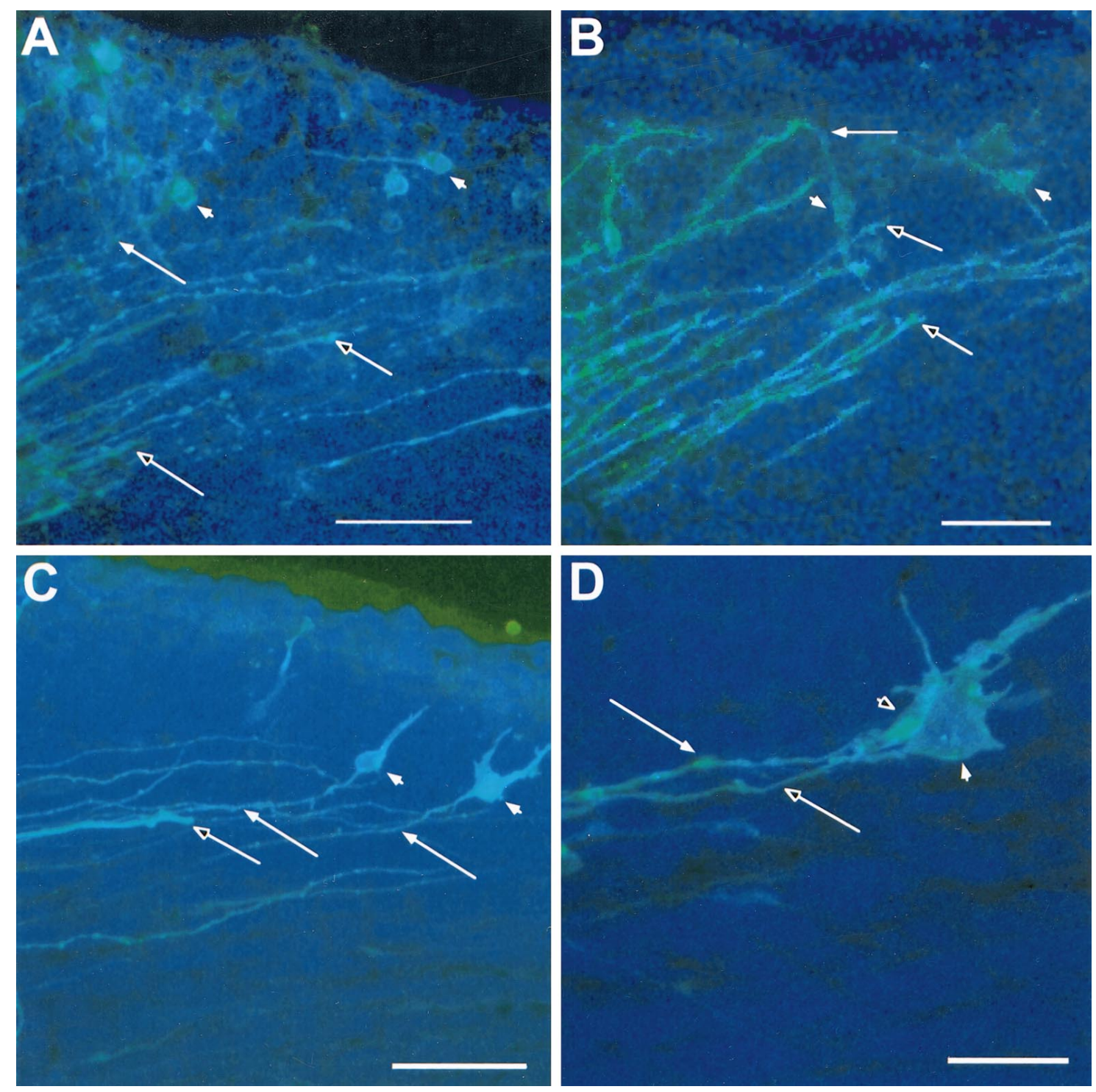

Figure 7. Further examples showing both efferent and afferent axons, labeled with a single crystal of DiI in the internal capsule of reeler. In these cases, thalamic axons have grown through the cortical plate and are invading the superplate layer. Each panel is an extended focus reconstruction, from a stack of thin confocal images, of part of the dorsolateral cortex of the left hemisphere (lateral is up; dorsal is right; pial surface near the top of each image). As in Figures 5 and 6, unfilled arrows mark definite thalamic fibers, identified by growth cones visible within the section; filled arrows show corticofugal axons that can be traced to cell bodies, which are themselves indicated with filled arrowheads. The sections in $A$, $C$, and $D$ were counterstained with acridine orange, and cell nuclei appear blue. Although the pial surface is not revealed in the bright-field image that forms the background in $B$, it lies immediately above the upper limit of the fluorescent axons and cells. $A$, In this example at E14.5, the most advanced thalamic fibers are entering the lower part of the superplate (similar to the examples in Figs. 5E, 6). B, This enlargement of part of the view in Figure $5 B$, also from an E14.5 reeler, shows some thalamic axons in the immediate vicinity of labeled superplate cell bodies. $C$, This view from an E15 reeler shows very clear association between a stout thalamic axon and the fiber of a bipolar superplate cell. Note that the thalamic axon lies in the middle of the array of fine corticofugal axons and is not segregated from them, even here, within the superplate layer. $D$, In this further example from an E15 reeler a back-labeled superplate cell (darker profile in front), whose chromatin, revealed with acridine orange counterstaining, appears blue here, lies immediately adjacent to and partly obscures a large bright profile, which contains no chromatic and is thus identified as a growth cone, presumably of a thalamic axon. The thalamic fiber and that of the preplate cell run parallel and in close association. The growth cone and the soma are so close together that no gap can be resolved between them in the three-dimensional reconstruction. Confocal reconstructions: $A$, 16 sections $\times 1.5 \mu \mathrm{m}$ intervals; $B, 32 \times 1.0 \mu \mathrm{m} ; C, 32 \times 1.6 \mu \mathrm{m} ; D, 32 \times 1.0 \mu \mathrm{m}$. Scale bars: $A, 200 \mu \mathrm{m} ; B, C, 50 \mu \mathrm{m} ; D, 10 \mu \mathrm{m}$.

\section{E18-P3: invasion and termination of thalamic axons in the cortical plate}

The waiting period in the occipital cortex of wild-type and reeler mice

Figure $8 A-D$ shows the patterns of distribution of axons labeled from the posterior dorsal thalamus in normal and reeler mice at E18, $>3$ d after they reach their target region in the occipital cortex. Single crystals in the dorsal thalamus still back-label no cell bodies in the cerebral wall and therefore reveal the thalamocortical projection alone. It is still indistinguishable in appearance in normal and reeler over most of its course. In both phenotypes, an approximately parallel array of thalamic axons streams through the primitive internal capsule and into the ventral intermediate zone. Only near the target area do the two phenotypes differ in appearance (Fig. 8, compare $A, C, B, D$ ).

In the occipital cortex of normal mice, the vast majority of 

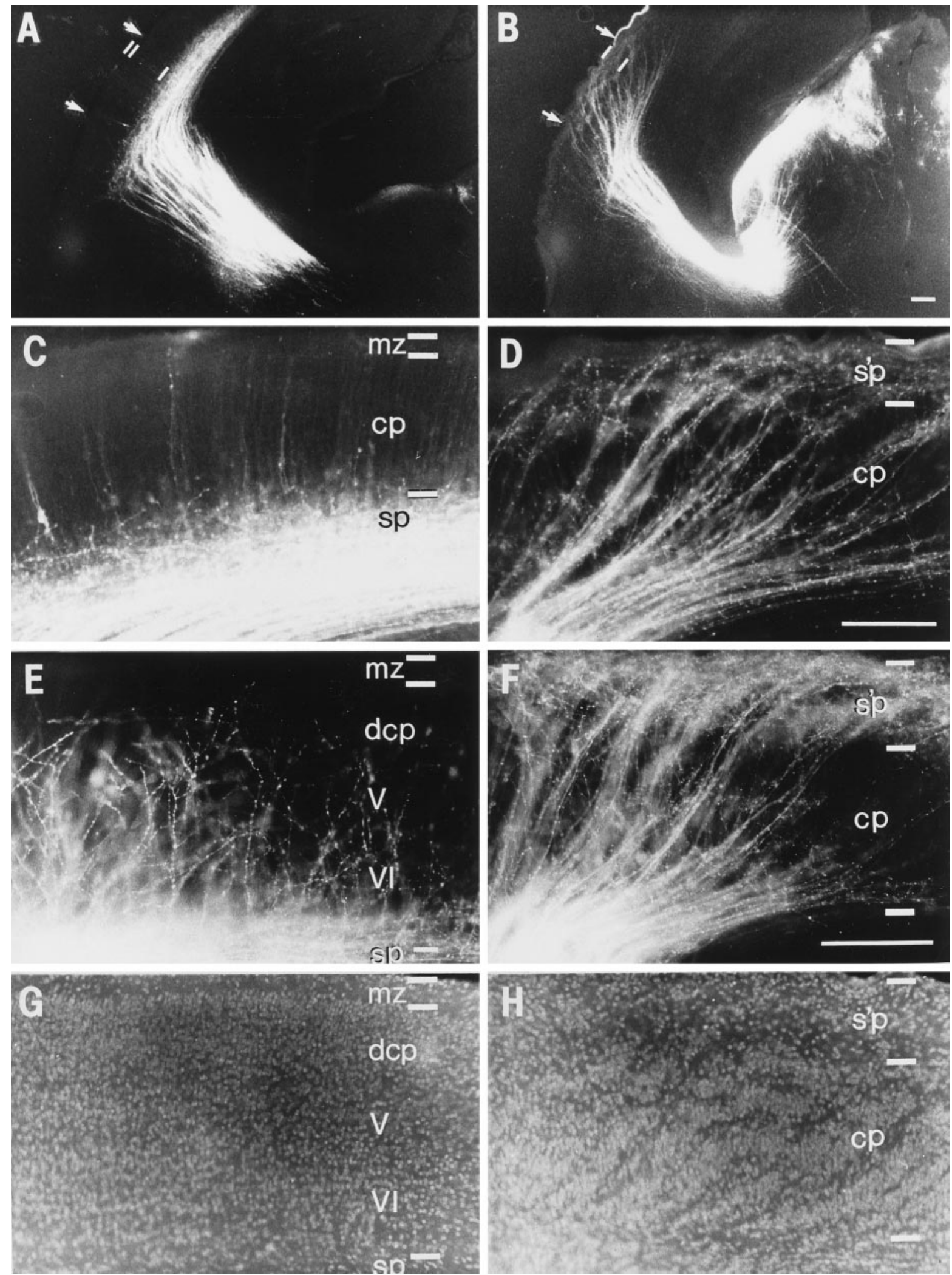

Figure 8. Behavior of thalamocortical axons at E18 $(A-D)$ and $\mathrm{P} 3(E-H)$, after their arrival at the cortex, in normal $(A, C, E$, $G)$ and reeler animals $(B$, $D, F, H)$. The dorsolateral segment of the occipital cortex of the left hemisphere is shown, as in Figures 4-7. A DiI crystal implanted in the posterior dorsal thalamus labeled thalamic fibers but virtually no cortical cell bodies. $A, C$, In the wild-type animal, at E18, $1 \mathrm{~d}$ before birth, most thalamic axons still appear to be waiting in the subplate $(s p)$ layer. The higher-power view $(C)$ shows a number of branches that have penetrated a short distance up into the cortical plate $(c p)$. One of the very rare back-labeled cortical cells in layer 6 is visible on the extreme left. In the background are weakly stained radial processes that extend up to the marginal zone $(m z)$; these are not axons and are probably transcellularly labeled radial glia. $B, D$, At E18 in the reeler, thalamic axons still occupy oblique fascicles through the cortical plate and end in the superplate (s'p) compartment. (Figure legend continues.) 
thalamic fibers have still not penetrated the cortical plate at E18 (Fig. 8A,C), even though they reached the occipital pole some days earlier. Only a small number of short side branches are seen entering the lowest part of the cortical plate (Fig. $8 C$ ). But in reeler, most if not all the thalamic fibers run in fascicles through the cortical plate, all the way up to the superplate, where they have gathered below the pial surface (Fig. $8 B, D$ ).

Thus, the superplate of reeler seems to play a role similar to that of the subplate in wild-type animals, both serving as compartments for the temporary accumulation of ingrowing thalamic axons. This observation is entirely compatible with the intimate relationship established in both phenotypes between thalamic axons and preplate fibers and suggests that the precocious efferent axons of preplate cells play an important part in guiding thalamic axons toward the waiting compartment.

\section{The immediate postnatal period: detachment from preplate cells}

We implanted a DiI crystal into the dorsal thalamus on both sides in all members of one litter at P1.5 $(n=7)$ and another at P3 $(n=$ $6)$. For each genotype, the distribution of thalamic axons at the cortex is similar at these two ages and substantially different from the picture at E18, $1 \mathrm{~d}$ or so before birth.

The change in the appearance of thalamic fibers is more immediately obvious in wild-type specimens; by P1.5 the majority of thalamic fibers appear to have left the subplate, turned sharply upward and grown approximately radially some distance into the cortical plate, just as at the equivalent stage in the rat (see Molnár et al., 1998). By P3 they have followed individual, somewhat erratic paths through the cortical plate, have arborized broadly, and apparently terminated some $200 \mu \mathrm{m}$ below the pial surface among cells that will presumably become layer 4 of the mature cortex (Fig. 8E).

In the postnatal reeler specimens, thalamic axons still occupy the characteristic oblique fascicles in which they ascended from the intermediate zone to the superplate region (Figs. $8 F, 9$ ). But close examination shows that most have now left the superplate, defasciculated, and turned sharply back down into the cortical plate as individual fibers, creating the odd "looping" pattern seen in adult reeler (Caviness, 1976). At this young age the overall downward distribution of the fine individual thalamic fibers is difficult to see in single planes of focus, because they are masked by the dense oblique fascicles (Fig. $9 A$ ). However, axons could be followed under high power, especially in the confocal microscope, looping out of the superplate layer and descending into the cortical plate below (Fig. 9C). After growing down through much of the depth of the gray matter in somewhat irregular patterns, many thalamic fibers appear, by P3, to have arborized broadly toward the bottom of the cortical plate. They are presumed to terminate among cells that have recently completed their migration (following the abnormal, outside-in pattern typical of reeler), whose birth dates are equivalent to those of layer 4 cells in normal animals (see Caviness 1982). At this depth and elsewhere in the cortical plate, we also saw short branches, originating directly from the ascending fascicles of thalamic fibers and terminating in close proximity to the main axons that have grown down from the superplate.

\section{Common topography of early corticofugal and thalamocortical projections}

In each member of one litter at E15, consisting of five wild type and six reeler, we implanted a small DiI crystal into the posterior half of the cortex. In each specimen a single, tight bundle of labeled axons can be traced down through the intermediate zone and internal capsule and up into the corresponding region of the diencephalon. Except very close to the cortex, the pattern of labeling is indistinguishable in wild type (Fig. 10A) and reeler (Fig. $10 B$ ). At the thalamic end of the bundle is a back-labeled cluster of cells, providing additional evidence that thalamic axons have reached their cortical target zones by this stage. Therefore, the labeled bundle within the intermediate zone must contain both early corticof ugal axons (mainly deriving from preplate cells at this early age) and the topographically corresponding thalamic afferents.

The fact that the labeled bundle is always discrete, narrow, and unitary over the whole of the resolvable part of its route strongly implies that the ascending axons are tightly associated with, perhaps fasciculated on, the pioneer corticof ugal fibers. Just as in the rat (Molnár et al., 1998), the single bundles of mixed efferent and afferent fibers labeled by crystals in the cortex at this early stage provides strong confirmation that the arrays of corticof ugal and thalamocortical axons occupy the same space within the intermediate zone in corresponding topographic order. This relationship appears to be essentially similar in reeler and wild-type animals.

In an E18 litter (four normal and six reeler), we implanted a number of different carbocyanine dyes in a parasagittal row along the convexity of the cortex and examined the mixed axon bundles and the back-labeled cells in the diencephalon. These experiments demonstrated a close similarity in the distribution and topography of corticofugal and thalamocortical projections in the two phenotypes. Figure $10, C$ and $D$, compares horizontal sections through the ventral part of the hemisphere of E18 wild-type and reeler mice, respectively, after placement of three different dye crystals along the cortex. The bundles of axons labeled by the three different dyes stay separate from each other, even as they pass through the constriction of the primitive internal capsule. They have the same relationship to each other in normal and reeler over both the telencephalic and the diencephalic portions of the pathway. And in both phenotypes, the anteroposterior sequence of crystal placement sites along the cortex corresponds to a mediolateral sequence of parallel slabs of back-labeled cells in the thalamus. Just as for

\section{$\longleftarrow$}

$C$ and $D$ were taken from the sectors indicated by arrows in $A$ and $B$, respectively. Scale bars, $100 \mu \mathrm{m} . E$, $G$, In the wild type at P3, bisbenzimide

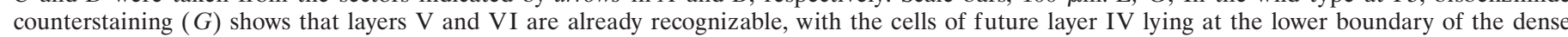

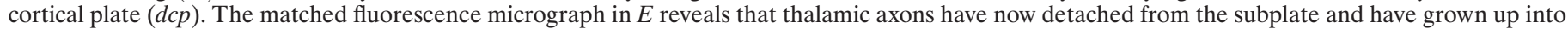

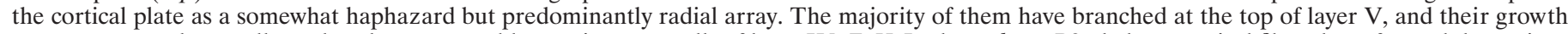

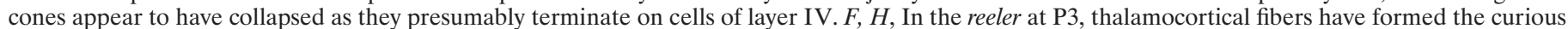

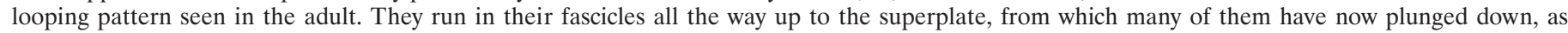

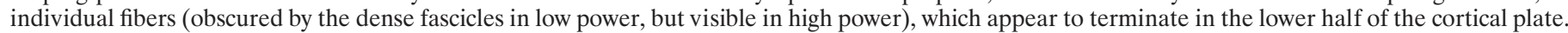

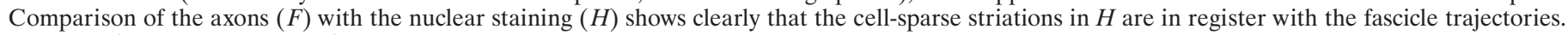
Scale bar (in $F$; applies to $E, F$ ), $200 \mu \mathrm{m}$. 

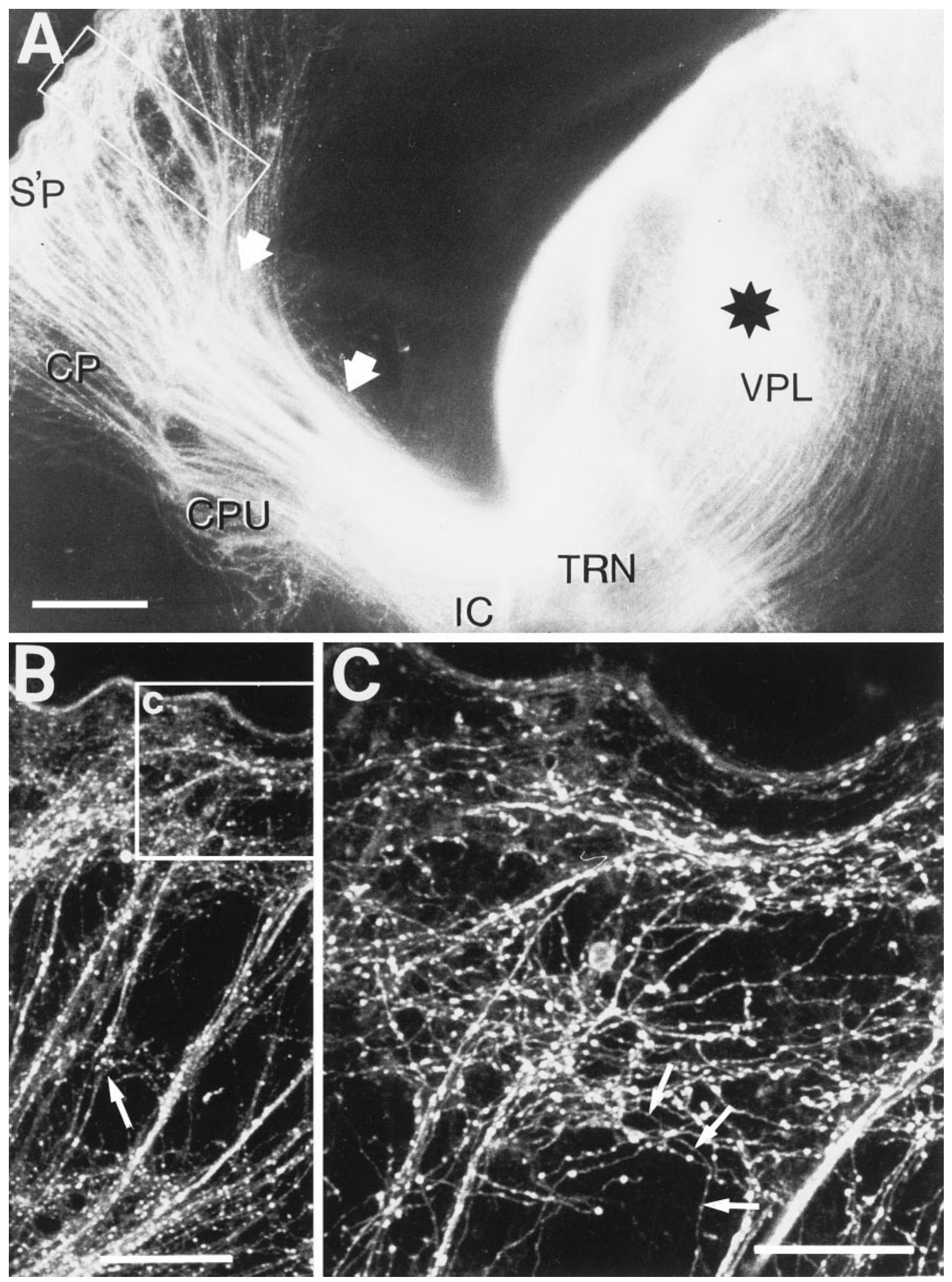

Figure 9. Thalamic axons were labeled with a DiI crystal (black star) placed in the vicinity of the nucleus ventralis posterolateralis (VPL) of the dorsal thalamus of the left hemisphere of a P3 reeler animal. The hemisphere was sectioned at an angle of $50^{\circ}$ to the sagittal plane so that the entire pathway to the lateral cortex could be seen in one $100-\mu \mathrm{m}$-thick section. $A$, Low-power fluorescence micrograph shows three distinct patterns of organization of thalamocortical axons in different parts of the pathway, the transitions between them marked by white, filled arrows. Within the body of the thalamus, the thalamic reticular nucleus $(T R N)$, ventral diencephalon, and internal capsule (IC), adjacent thalamic axons usually remain approximately parallel, separate but closely associated. As it passes through the basal ganglia, dorsal to the caudate-putamen $(C P U)$, the tightly packed, homogeneous array reorganizes (at the right arrow) into small, tight fascicles. At the lateral edge of the striatum (left arrow) the fibers do not defasciculate (as in the normal animal) but run all the way up in characteristic fascicles through the cortical plate $(C P)$ to the superplate $\left(S^{\prime} P\right)$. $B$, Confocal micrograph in the region indicated by the outline box in $A$, showing thalamic axons running up in oblique fascicles, looping through the superplate (Figure legend continues.), 

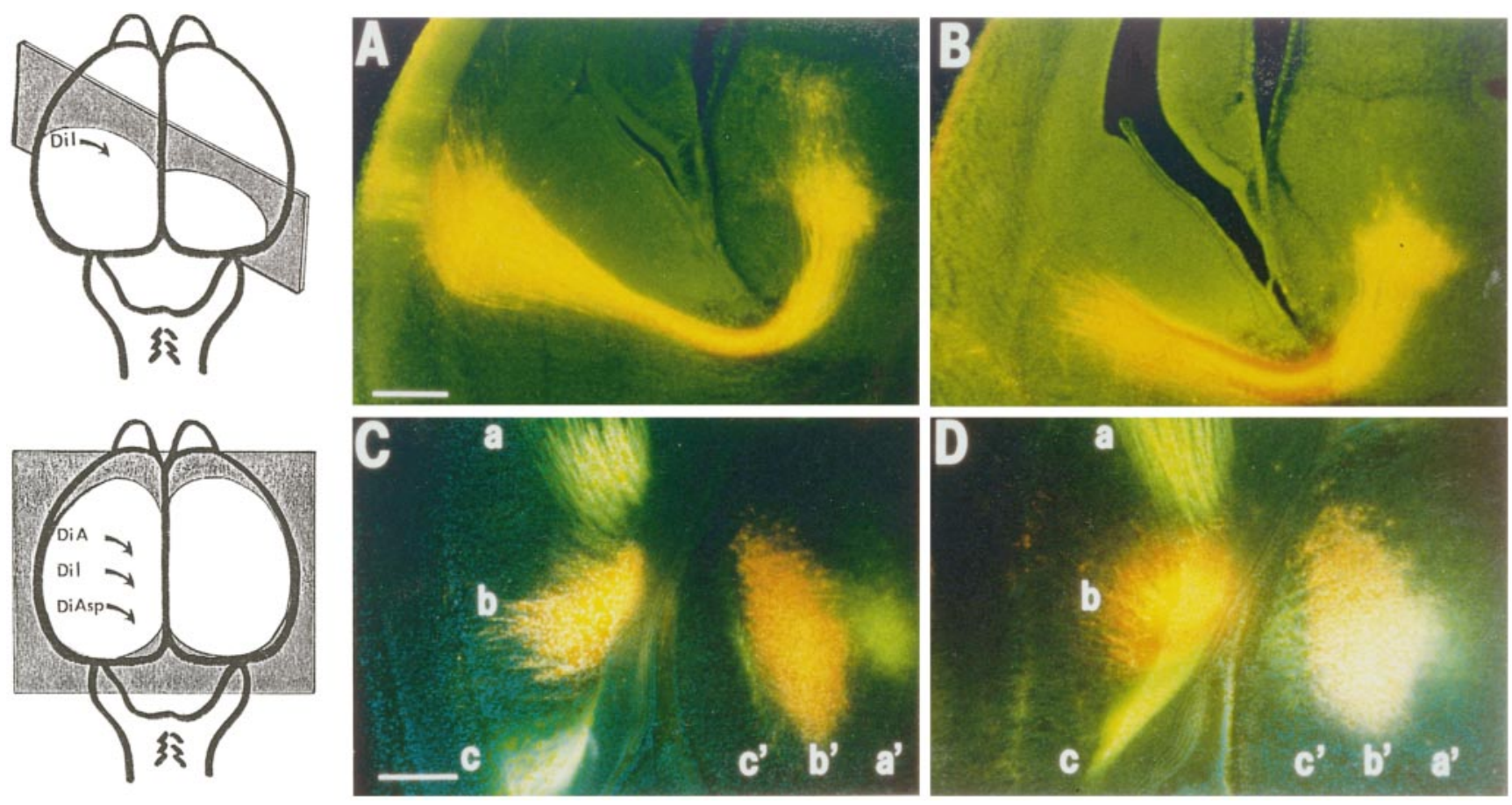

Figure 10. Cortical crystal placements at E15 $(A, B)$ and at E18 $(C, D)$ after the arrival of thalamic axons reveal indistinguishable global relationships between thalamus and cortex in wild-type $(A, C)$ and reeler $(B, D)$ phenotypes. $A, B$, Low-power fluorescence photomicrographs, taken with double exposure (to show DiI and bisbenzimide), of sections from E15 normal $(A)$ and reeler $(B)$ mice from the same litter. A small DiI crystal was placed in the cortex of all members of this litter (5 wild-type, 6 reeler), quite lateral in the left hemisphere in these two cases. Sections (200 $\mu \mathrm{m}$ thick) were cut vertically, at an angle of $45^{\circ}$ to coronal (indicated by the shaded plane in the schematic drawing on the left), so that most of the pathway, from left lateral cortex to ventral thalamus, could be followed within a single section. (The site of crystal placement was visible in an adjacent section.) In both wild type and reeler, a discrete labeled bundle (a mixture of corticof ugal and thalamocortical axons over much of its course) descends through the intermediate zone and internal capsule and then extends up to a group of back-labeled cells in the ventrobasal thalamus. $C, D$, Small crystals of three different carbocyanine dyes (DiA, DiI, and DiAsp) were placed in a parasagittal line along the convexity of the left hemisphere (see schematic drawing on the left ) of all brains in an E18 litter (4 normal, 6 reeler). From corresponding horizontal sections, just above the junction of telencephalon and diencephalon, in a wild type $(C)$ and a reeler $(D)$, triple-exposure pictures were taken to show all three dyes and the bisbenzimide counterstaining (DiI appears orange, DiAsp and DiA yellow-green). In each phenotype, the crystals labeled three distinct and separate fiber bundles $(a-c)$, which could be followed, in successive horizontal sections, sweeping down from the cortex to the internal capsule, passing through, rotating $\sim 90^{\circ}$ in the ventral diencephalon (below the level of these sections), with each running toward an anteroposteriorly elongated group of labeled thalamic cells $\left(a^{\prime}-c^{\prime}\right)$. The global topography of the thalamocortical system seems indistinguishable in the two phenotypes. Scale bars: $A, B, 500 \mu \mathrm{m} ; C, D, 300 \mu \mathrm{m}$.

the normal rat (Molnár et al., 1998), this implies that there is a single $90^{\circ}$ rotation of the axon array in the ventral diencephalon in both wild-type and reeler mice.

\section{No cortical neurons reach the dorsal thalamus before P3}

Cells of the Preplate (subplate and marginal zone of normal animals and superplate of reeler) were readily back-labeled from dye crystals in the primitive internal capsule at E13-E14.5 (Figs. $2,5,6,7)$. But over the entire age range studied, up to and including P3, small dye crystals placed directly in parts of the dorsal thalamus, well away from the ventral diencephalon and the primitive internal capsule, retrogradely labeled virtually no cell bodies in the cerebral wall. This was true not only for the presumptive preplate but also for the true cortical plate (Figs. 4,
$8,9)$. Increasing the incubation period for dye transport by an additional few weeks did not lead to the appearance of label in cortical neurons. This strongly suggests not only that the axons of preplate cells stop short of the thalamus, as in the normal rat (Molnár et al., 1998), but also that the fibers of true corticothalamic neurons have not invaded the dorsal thalamus of the mouse, even several days after birth.

\section{DISCUSSION}

The apparently normal regional and laminar targeting by thalamic afferents in the reeler mouse, despite the radical disorganization of corticogenesis, poses a challenge for models of thalamocortical development. In particular, the hypothesis that early postmitotic cells, which normally lie in a strategic position in the

and then dispersing as fine individual axons that can be seen at higher power plunging back down into the cortical plate. At this stage a few fine side branches appear from axons in the oblique bundles near the bottom of the cortical plate ( filled arrowheads). Extended focus reconstruction: 32 sections at $2 \mu \mathrm{m}$ intervals. $C$, This higher-power view of the region of the superplate (from the outlined area in $B$ ) shows the plexus of axons that have left the oblique fascicles, starting to establish the looping pattern so characteristic of the thalamic innervation in the adult reeler (Caviness, 1976). Although at this age, the fine, individual axons are difficult to resolve against the dense fascicles and the superficial plexus, some can be seen running downward into the cortical plate (arrowheads). In the microscope, single axons can be followed down to the lower half of the cortical plate, where their growth cones have collapsed, and they are presumably terminating on cortical neurons. Extended focus reconstruction: 32 sections at $0.5 \mu \mathrm{m}$ intervals. Scale bars: $A$, $250 \mu \mathrm{m} ; B, 100 \mu \mathrm{m} ; C, 50 \mu \mathrm{m}$. 


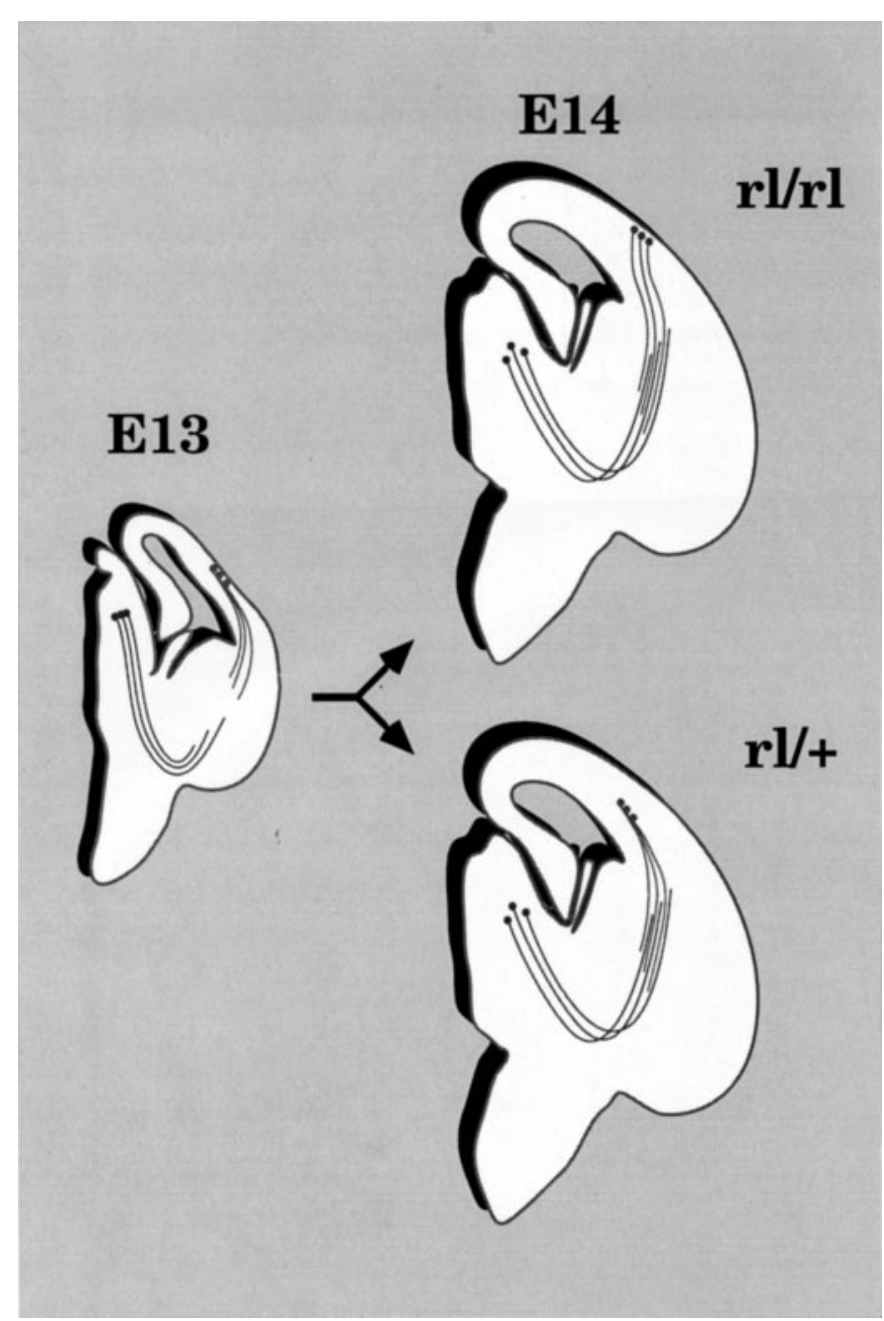

Figure 11. Schematic summary of the establishment of early corticofugal and corticopetal projections in normal and reeler phenotypes. Each diagram represents an imaginary section through the right hemisphere, revealing the entire pathway. At E13 (left diagram) the formation of the preplate, the outgrowth of descending corticofugal axons, and the concomitant growth of thalamic axons through the primitive internal capsule all occur indistinguishably in reeler and normal animals. But by E14 (right diagrams), as thalamic axons are approaching their target areas, the cortical plate itself has started to form, and the distinctive differences in the phenotypes begin to emerge. In reeler $(r l / r l)$ the plate forms under all the preplate (now superplate) cells, whose pioneer axons gather into oblique fascicles, running through the thickening plate. Thalamic axons follow these fibers up to the superplate layer. In the wild type $(\mathrm{rl} /+,+/+)$, the majority of corticofugal axons derive from those preplate cells that come to lie below the cortical plate in the subplate.

subplate below the cortical plate, play a role in both the guidance and the holding of thalamic axons (Blakemore and Molnár, 1990; Shatz et al., 1990), seems incompatible with the aberrant location of such cells above the cortical plate in the superplate of reeler. However, far from falsifying the "handshake hypothesis," our studies of the early development of reeler suggest that thalamic axons follow precisely the same algorithm of interaction with the axons and cell bodies of early-born cortical neurons and that this parsimoniously accounts for the otherwise mysterious, looping trajectories of thalamic fibers previously described in mature reeler (Caviness, 1976).

The timing and the overall topography of the initial corticofugal and thalamofugal projections are essentially identical in nor- mal and reeler mice. During the earliest stages of thalamocortical development, at approximately E13-E13.5, the cortical preplate, the thalamus, and their projections are indistinguishable in the two. Cells of the preplate extend pioneering axons before the migration of any cells of the cortical plate proper and before the arrival of afferents from the thalamus or brainstem (Crandall et al., 1992). By E13.5 these descending axons approach the primitive internal capsule, with a similar degree of fiber order in the two genotypes. At approximately the same stage, axons from the thalamus have grown, in topographic order, through the primitive internal capsule and are approaching their corticof ugal counterparts. Thalamic fibers distribute to the appropriate cortical regions, intimately mixed with the corresponding pioneer preplate axons, establishing the same simple topographic relationship between the volume of the thalamus and the cortical sheet in wild type and reeler (Fig. 10).

\section{Preplate cells as temporary targets}

Differences between reeler and wild type start to become evident immediately after the arrival of the first neurons of the cortical plate, which stop below the preplate in reeler rather than penetrating and splitting it (Goffinet, 1979; Pinto-Lord and Caviness, 1979). The abnormal disposition of the cortical plate in reeler changes the appearance of the preexisting preplate axons, restricting them to oblique fascicles, running down through the cortical plate from the superplate above. But this does not alter their appearance in the basal telencephalon, where they have already made contact with the array of thalamic axons advancing toward the cortex, just as in the normal animal.

When they reach the cortex, thalamic axons behave very differently in the two genotypes. In normal mice, as in rats (Molnár et al., 1998), the vast majority accumulate for a couple of days or so in the subplate (at least for the occipital cortex) and then grow up radially into the cortical plate, terminating mainly in layer 4 . In reeler, thalamic fibers appear to penetrate the cortical plate as soon as they arrive and run diagonally up to the superplate layer, where they wait before turning down into the plate itself. However, both patterns are entirely compatible with the hypothesis that thalamic axons follow the scaffold of corticofugal preplate fibers toward their cell bodies. Figure 11 is a schematic summary of these findings.

\section{Mechanisms of guidance and targeting}

The normal tangential topography of thalamocortical projections in reeler (Caviness and Frost, 1980; Caviness and Korde, 1981; Crandall and Caviness, 1984; Yamamoto et al., 1986; Caviness et al., 1988) has been cited as evidence that thalamic axons are guided by diffusible substances originating from cortical target cells (Caviness and Rakic, 1978; Caviness et al., 1988) rather than by contact with preformed axonal pathways. Co-culture studies (Molnár and Blakemore, 1991; Bolz et al., 1992; Yamamoto et al., 1992; Rennie et al., 1994) have revealed that the cortex has a remote, growth-promoting influence on the outgrowth of thalamic axons, but there is no obvious regional specificity in this effect (Molnár and Blakemore, 1991), and it seems inconceivable that it could generate the topographic regularity of the thalamic projection seen in vivo (Molnár and Blakemore, 1995).

Observations in vitro also suggest that cells of the occipital cortical plate do not express surface properties that permit invasion by thalamic axons until several days after those axons arrive under the cortex in vivo (Bolz et al., 1992; Götz et al., 1992; 
Hübner et al., 1992; Molnár and Blakemore, 1995; Tuttle et al., 1995). Indeed, the onset of such growth-permissive characteristics may partly explain why thalamic fibers detach from the subplate at the end of the waiting period. If the cortical plate of reeler is also nonpermissive for thalamic axons when they first arrive, their passage in diagonal fascicles through the plate to the superplate above must depend on the existence of privileged pathways through the hostile territory of the plate itself. Because thalamic axons appear to grow through the intermediate zone in association with the fibers of preplate (i.e., superplate) neurons, we conclude that the oblique fascicles that those preplate fibers form within the accumulating cortical plate constitute the privileged pathway that thalamic axons follow. This proposal is directly supported by observation of identified thalamic fibers running in close association with superplate axons, right up to their somata (Figs. 5-7). Thus, not only do preplate cells act as temporary targets for thalamic fibers, but their axons may also constitute a guidance pathway to those targets, in reeler as well as in normals.

Caviness et al. (1988) suggested that the oblique fascicles that they saw crossing the thickness of the developing cortical plate in reeler (labeled with the rapid Golgi technique) might consist only of thalamic fibers, but when similar preparations were stained by neurofilament immunohistochemistry, the same bundles appeared larger. Caviness et al. (1988) therefore suggested that the fascicles, which they called "plexiform tributaries," include the fibers of superplate cells, running together with the thalamic axons. Our observations strongly support this suggestion.

Interestingly, even in wild-type mice, small numbers of thalamocortical axons approach the marginal zone by growing obliquely through the cortical plate as soon as they arrive at the cortex (Fig. 4E). Early innervation of the marginal zone has also been reported in E14 hamsters (Miller et al., 1993). In concordance with this, we saw a small population of cells in the marginal zone of normal mice that have axons projecting down to the primitive internal capsule at very early stages, before the arrival of thalamic axons, just like the superplate cells of reeler. We suggest that the rare thalamic fibers that precociously grow up to the marginal zone in normal animals follow the descending axons of those cells, just like the whole population in reeler. At somewhat later stages, marginal zone cells can no longer be backlabeled from the internal capsule in normal animals (Molnár et al., 1998; McConnell et al., 1989), so presumably they die or withdraw their axons.

Chondroitin sulfate core proteins (Bicknese et al., 1994a; Miller et al., 1995), with glycosaminoglycan side chains (Derer and Nakanishi, 1983), as well as specific peanut agglutinin lectin binding (Götz et al., 1992), are selectively expressed in the subplate layer of normal rodents. The axons of subplate neurons in normal animals also express the surface molecules L1 (Godfraind et al., 1988; Chung et al., 1991) and fibronectin (Stewart and Pearlman, 1987; Chun and Shatz, 1988; Sheppard et al., 1991). The early-born cortical neurons of reeler, despite their aberrant location, also express glycosaminoglycans (Derer and Nakanishi, 1983; Godfraind et al., 1988; Bicknese et al., 1994b) and other adhesion molecules (L1, neural cell adhesion molecule, and fibronectin). Moreover, glycosaminoglycans and peanut agglutinin lectin binding are also expressed along the oblique striations that cross the cortical plate in reeler (Bicknese et al., 1994b), which contain the axons of superplate cells. Thus, a variety of attractive surface molecules exist on the axons of preplate cells, which in reeler could provide the privileged pathway needed for the early growth of thalamic axons through the cortical plate.

Co-culture of thalamic and cortical explants from normal rats has revealed a temporal cascade of cortical properties (growthpromotion, growth-permissive, and a "stop signal" in layer 4), which might contribute to the timing of outgrowth, waiting, invasion, and termination of thalamic axons but is unlikely to account for their topographic distribution (Molnár and Blakemore, 1991, 1995). If such factors are similarly expressed in reeler, they could also play a part in determining the sequence of events and the final termination of thalamic fibers in the equivalent of layer 4. Interestingly, thalamic axons do not selectively innervate the rat subplate layer in co-culture experiments (Molnár and Blakemore, 1991; Molnár, 1998). We have taken this to imply that the normal, quite precise positional targeting of thalamic axons and their accumulation in the subplate in vivo are at least partly dependent on the establishment of an intimate relationship between thalamic and subplate axons during the hypothesized handshake in the ventral telencephalon (Molnár and Blakemore, 1995). Our observations in reeler support this suggestion.

Ghosh et al. (1990) and Ghosh and Shatz (1993) have shown that selective destruction of the subplate layer in normal cats, after the arrival of thalamic axons, prevents the innervation of the cortex. It would be interesting to perform similar experiments in reeler, lesioning the superplate before the arrival of thalamic axons, to see whether this would prevent the precocious ingrowth of the thalamic fibers.

In conclusion, thalamocortical development in reeler strengthens the hypothesis that the preplate scaffold serves a guiding role for thalamic axons. Selective fasciculation of growing fibers on a network of pioneer axons, an established mechanism of guidance in insects (Goodman et al., 1984), appears to operate in the mammalian thalamocortical pathway.

\section{REFERENCES}

Angevine Jr JB, Sidman RL (1961) Autoradiographic study of cell migration during histogenesis of cerebral cortex in the mouse. Nature 192:766-768.

Bar I, Lambert de Rouvroit C, Royaux I, Kritzman DB, Dernoncourt C, Ruelle D, Beckers MC, Goffinet AM (1995) A YAC contig containing the reeler locus with preliminary characterization of candidate gene fragments. Genomics 26:543-549.

Bayer SA, Altman J (1991) Neocortical development. New York: Raven.

Bicknese AR, Sheppard AM, O'Leary DDM, Pearlman AL (1994a) Thalamocortical axons extend along a chondroitin sulfate proteoglycan-enriched pathway coincident with the neocortical subplate and distinct from the efferent path. J Neurosci 14:3500-3510.

Bicknese AR, Wang W, Sharma A (1994b) Multiple guidance cues are involved in the segregation of pioneering pathways in the cortex and internal capsule: evidence from reeler. Soc Neurosci Abstr 20:1683.

Blakemore C, Molnár Z (1990) Factors involved in the establishment of specific interconnections between thalamus and cerebral cortex. Cold Spring Harb Symp Quant Biol 55:491-504.

Bolz J, Novak N, Staiger V (1992) Formation of specific afferent connections in organotypic slice cultures from rat visual cortex cocultured with lateral geniculate nucleus. J Neurosci 12:3054-3070.

Catalano S, Robertson RT, Killackey HP (1991) Early ingrowth of thalamocortical afferents to the neocortex of the prenatal rat. Proc Natl Acad Sci USA 88:2999-3003.

Catalano S, Robertson RT, Killackey HP (1996) Individual axon morphology and thalamocortical topography in developing rat somatosensory cortex. J Comp Neurol 367:36-53.

Caviness Jr VS (1976) Patterns of cell and fiber distribution in the neocortex of the reeler mutant mouse. J Comp Neurol 170:435-448.

Caviness Jr VS (1982) Neocortical histogenesis in normal and reeler mice: a developmental study based upon $\left[{ }^{3} \mathrm{H}\right]$ thymidine autoradiography. Dev Brain Res 4:293-302. 
Caviness Jr VS, Frost DO (1980) Tangential organization of thalamic projections of the neocortex in the mouse. J Comp Neurol 194:355-367. Caviness Jr VS, Korde MG (1981) Monoaminergic afferents to the neocortex: a developmental histofluorescence study in normal and reeler mouse embryos. Brain Res 209:1-9.

Caviness Jr VS, Rakic P (1978) Mechanisms of cortical development: a view from mutations in mice. Annu Rev Neurosci 1:297-326.

Caviness Jr VS, Sidman RL (1973) Time of origin of corresponding cell classes in the cerebral cortex of normal and reeler mutant mice: an autoradiographic analysis. J Comp Neurol 170:449-460.

Caviness Jr VS, Crandall JE, Edwards MA (1988) The reeler malformation, implications for neocortical histogenesis. In: Cerebral cortex, Vol 7 (Jones EG, Peters A, eds), pp 489-499. New York: Plenum.

Chun JJM, Shatz CJ (1988) A fibronectin-like molecule is present within the developing cat cerebral cortex and is correlated with subplate neurons. J Cell Biol 106:857-872.

Chung WW, Lagenaur CF, Yan YM, Lund JS (1991) Developmental expression of neuronal cell adhesion molecules in the mouse neocortex and olfactory bulb. J Comp Neurol 314:290-305.

Crandall JE, Caviness Jr VS (1984) Axon strata of the cerebral wall in the embryonic mice. Dev Brain Res 14:185-195.

Crandall JE, Hassinger LC, Bonacorso J (1992) Afferents to preplate neurons in embryonic mouse cortex. Soc Neurosci Abstr 18:778.

D'Arcangelo G, Miao GG, Chen S-C, Soares HD, Morgan JI, Curran T (1995) A protein related to extracellular matrix proteins deleted in the mouse mutant reeler. Nature 374:719-723.

De Carlos JA, O'Leary DDM (1992) Growth and targeting of subplate axons and establishment of major cortical pathways. J Neurosci 12:1194-1211.

Derer P, Nakanishi S (1983) Extracellular matrix distribution during neocortical wall ontogenesis in normal and reeler mice. J Hirnforsch 24:209-224.

Dräger UC (1976) Reeler mutant mice: physiology in primary visual cortex. Exp Brain Res [Suppl] 1:274-276.

Erzurumlu RS, Jhaveri S (1992) Emergence of connectivity in the embryonic rat parietal cortex. Cereb Cortex 2:336-352.

Frost DO, Caviness Jr VS (1980) Radial organization of thalamic projections to the neocortex in the mouse. J Comp Neurol 194:369-393.

Ghosh A, Shatz CJ (1992) Pathfinding and target selection by developing geniculocortical axons. J Neurosci 12:39-55.

Ghosh A, Shatz CJ (1993) A role for subplate neurons in the patterning of connections from thalamus to neocortex. Development 117:1031-1047.

Ghosh A, Antonini A, McConnell SK, Shatz CJ (1990) Requirement for subplate neurons in the formation of thalamocortical connections. Nature 347:179-181.

Godement P, Vanselow J, Thanos S, Bonhoeffer F (1987) A study in developing visual systems with a new method of staining neurones and their processes in fixed tissue. Development 101:697-713.

Godfraind C, Schachner M, Goffinet AM (1988) Immunohistochemical localisation of cell adhesion molecules L1, J1, N-CAM and their common carbohydrate L 2 in the embryonic cortex of normal and reeler mice. Dev Brain Res 42:99-111.

Goffinet AM (1979) An early developmental defect in the cerebral cortex of the reeler mouse. Anat Embryol 157:205-216.

Goffinet AM (1980) The cerebral cortex of the reeler mouse embryo: an electron microscopic analysis. Anat Embryol 159:199-210.

Goffinet AM (1984) Events governing organization of postmigratory neurons: studies on brain development in normal and reeler mice. Brain Res Rev 7:261-296.

Goffinet AM (1995) A real gene for reeler. Nature 374:675-676.

Goffinet AM, Lyon G (1979) Early histogenesis in the mouse cerebral cortex: a Golgi study. Neurosci Lett 14:61-66.

Goodman CS, Bastiani MJ, Doe CQ, Shelfand duLac S, Kuwada JY, Thomas B (1984) Cell recognition during neuronal development. Science 225:1271-1279.

Götz M, Novak N, Bastmayer M, Bolz J (1992) Membrane-bound molecules in rat cerebral cortex regulate thalamic innervation. Development 116:507-519.

Hoffarth R, Johnston JG, Krushel LA, van der Kooy D (1995) The mouse mutation reeler causes increased adhesion within a subpopulation of early postmitotic cortical neurons. J Neurosci 15:4838-4850.

Hübener M, Götz M, Klostermann S, Bolz J (1992) Growth behavior of thalamic axons on cortical membranes studied with time-lapse video microscopy. Soc Neurosci Abstr 18:924.
Jones EG (1985) The thalamus. New York: Plenum.

Kageyama GH, Robertson RT (1993) Development of geniculocortical projections to visual cortex in rat: evidence for early ingrowth and synaptogenesis. J Comp Neurol 335:123-14.

König N, Valat J, Fulcrand J, Marty R (1977) The time of origin of Cajal-Retzius cells in the rat temporal cortex. An autoradiographic study. Neurosci Lett 4:21-26.

Luskin MB, Shatz CJ (1985a) Neurogenesis of the cat's primary visual cortex. J Comp Neurol 242:611-631.

Luskin MB, Shatz CJ (1985b) Studies of the earliest-generated cells of the cat's visual cortex: cogeneration of subplate and marginal zones. J Neurosci 5:1062-1075.

Marin-Padilla M (1971) Early prenatal ontogenesis of the cerebral cortex (neocortex) of the cat (Felis domestica): a Golgi study. I. The primordial neocortical organization. Z Anat Entwicklungsgesch 134:117-145.

Marin-Padilla M (1988) Early ontogenesis of the human cerebral cortex. In: Cerebral cortex, Vol 7 (Peters A, Jones EG, eds), pp 1-34. New York: Plenum.

McConnell SK, Gosh A, Shatz CJ (1989) Subplate neurons pioneer the first axon pathway from the cerebral cortex. Science 245:978-982.

Miller B, Chou L, Finlay BL (1993) The early development of thalamocortical and corticothalamic projections. J Comp Neurol 335:16-41.

Miller B, Sheppard AM, Bicknese AR, Pearlman AM (1995) Chondroitin sulfate proteoglycans in the developing cerebral cortex: the distribution of neurocan distinguishes forming afferent and efferent axonal pathways. J Comp Neurol 355:615-628.

Molnár Z (1998) Development of thalamocortical connections. Neuroscience Intelligence Unit Series. Austin, TX: Landes.

Molnár Z, Blakemore C (1990) Relationship of corticofugal and corticopetal projections in the prenatal establishment of projections from thalamic nuclei to the specific cortical areas of the rat. J Physiol (Lond) 430:104P.

Molnár Z, Blakemore C (1991) Lack of regional specificity for connections formed between thalamus and cortex in co-culture. Nature 351:475-477.

Molnár Z, Blakemore C (1992) How are thalamocortical axons guided in the reeler mouse? Soc Neurosci Abstr 18:778.

Molnár Z, Blakemore C (1995) How do thalamic axons find their way to the cortex? Trends Neurosci 18:389-397.

Molnár Z, Adams R, Blakemore C (1998) Mechanisms underlying the early establishment of thalamocortical connections in the rat. J Neurosci 18:5723-5745.

Ogawa M, Miyata T, Nakajima K, Yagyu K, Seike M, Ikenaka K, Yamamoto H, Mikoshiba K (1995) The reeler gene-associated antigen on Cajal-Retzius Neurons is a crucial molecule for laminar organization of cortical neurons. Neuron 14:899-912.

Pinto-Lord MC, Caviness Jr VS (1979) Determinants of cell shape and orientations: a comparative Golgi analysis of cell-axon interrelationships in the developing neocortex of normal and reeler mice. J Comp Neurol 187:49-70.

Rakic P (1976) Prenatal genesis of connections subserving ocular dominance in the rhesus monkey. Nature 261:467-471.

Rakic P (1977) Prenatal development of the visual system in the rhesus monkey. Philos Trans R Soc Lond B Biol Sci 278:245-260.

Rakic P (1988) Specification of cerebral cortical areas. Science 241:170-176.

Rakic P, Caviness Jr VS (1995) Cortical development: view from neurological mutants two decades later. Neuron 14:1101-1104.

Rennie S, Lotto RB, Price DJ (1994) Growth-promoting interactions between the murine neocortex and thalamus in organotypic co-cultures. Neuroscience 61:547-564.

Rickmann M, Chronwall M, Wolff JR (1977) On the development of non-pyramidal neurons and axons outside the cortical plate: the early marginal zone as a pallial anlage. Anat Embryol 151:285-307.

Shatz CJ, Luskin MB (1986) Relationship between the geniculocortical afferents and their cortical target cells during development of the cat's primary visual cortex. J Neurosci 6:3655-3668.

Shatz CJ, Chun JJM, Luskin MB (1988) The role of the subplate in the development of the mammalian telencephalon. In: Cerebral cortex, Vol. 7 (Peters A, Jones EG, eds), pp 35-58. New York: Plenum.

Shatz CJ, Ghosh A, McConnell SK, Allendoerfer KL, Friauf E, Antonini A (1990) Pioneer Neurons and target selection in cerebral cortical development. Cold Spring Harb Symp Quant Biol 55:469-480. 
Sheppard AM, Hamilton SK, Pearlman AL (1991) Changes in the distribution of extracellular matrix components accompany early morphogenetic events of mammalian cortical development. J Neurosci 11:3928-3942.

Sidman RL, Miale L, Feder N (1959) Cell proliferation and migration in the primitive ependymal zone: an autoradiographic study of histogenesis in the nervous system. Exp Neurol 1:322-333.

Simmons PA, Pearlman AL (1982) Retinotopic organization of the striate cortex (area 17) in the reeler mutant mouse. Dev Brain Res 4:124-126.

Stanfield BB, Cowan WM (1979) The development of the hippocampus and dentate gyrus in normal and reeler mice. J Comp Neurol 185:423-460.

Steindler DA, Colwell SA (1976) Reeler mutant mouse: maintenance of appropriate and reciprocal connections in the cerebral cortex and thalamus. Brain Res 105:386-393.
Stewart GR, Pearlman AL (1987) Fibronectin-like immunoreactivity in the developing cerebral cortex. J Neurosci 7:3325-3333.

Tuttle R, Schlaggar BL, Braisted JE, O'Leary DDM (1995) Maturationdependent upregulation of growth-promoting molecules in developing cortical plate controls thalamic and cortical neurite growth. J Neurosci 15:3039-3052.

Yamamoto M, Boyer AB, Crandall JE, Edwards MA, Tanaka H (1986) The distribution of stage-specific neurite-associated proteins in the developing murine nervous system recognized by a monoclonal antibody. J Neurosci 6:3576-3594.

Yamamoto N, Yamada K, Kurotani T, Toyama K (1992) Laminar specificity of extrinsic cortical connections studied in culture preparations. Neuron 9:217-228.

Yuasa S, Kitoh J, Kawamura K (1994) Interactions between growing thalamocortical afferent axons and the neocortical primordium in normal and reeler mutant mice. Anat Embryol 190:137-154. 